\title{
LAS RELACIONES DE VECINDAD Y LA TEORÍA DE LAS INMISIONES EN EL Código CiVIL
}

["Vicinity Relationships and the Immissions Theory in the Civil Code"]

\author{
Carlos Felipe Amunátegui Perelló* \\ Pontificia Universidad Católica de Chile, Santiago, Chile
}

\begin{abstract}
RESUMEN
El artículo trata sobre la posibilidad de aplicar la teoría de las inmisiones para regular las relaciones de vecindad dentro del marco normativo establecido en nuestro Código Civil. Para ello se analizan la definición de propiedad del artículo 582, las servidumbres legales y las acciones posesorias a fin de establecer la recepción de los casos sobre los cuales se construye dicha teoría en nuestro Derecho positivo.
\end{abstract}

\section{Palabras Clave}

Inmisiones - Acción negatoria - Servidumbres legales - Acciones posesorias

\begin{abstract}
This article deals with the possibility of applying the immissions theory to regulate neighborly relationships within the regulatory framework established in our Civil Code. To this end, the definition of property in article 582, the legal easements and possessory actions are analyzed in order to establish the reception of the cases underlying that theory in our positive Law.

KEYWORDS
Immissions - Negatory actions - Le-
gal easement - Possessory actions

KEYWORDS

gal easement - Possessory actions
\end{abstract}

RECIBIDo 25 de abril el de y ACEPTADo el 22 de mayo de 2012.

* Profesor de Derecho romano de la Facultad de Derecho de la Pontificia Universidad Católica de Chile. Dirección postal: Facultad de Derecho, Pontificia Universidad Católica de Chile, Avenida Bernardo O’Higgins 340, Santiago, Chile. Correo electrónico: camunate@uc.cl. El presente artículo se hace en cumplimiento del proyecto regular FONDECYT No 1100452 


\section{INTRODUCCIÓN.}

\section{LOS LÍMITES DE LA PROPIEDAD PRIVADA EN INTERÉS PRIVADO}

Los límites de la propiedad son un tema extensamente tratado por jurisprudencia, tanto judicial como doctrinaria, desde la perspectiva de su función social. Al efecto, el devenir histórico de nuestro país obligó a un detallado examen de la cuestión durante todo el siglo XX, en que el concepto de dominio pasó por un severo análisis desde el punto de vista de su función, de su protección y, en último término, de su conveniencia ética y política, dada la tradicionalmente desigual distribución de la riqueza en Chile y la fuerza de los movimientos sociales y políticos que fijaron como objetivo fundamental su redistribución. Los resultados de este proceso, que pasaron por la violencia como último argumento, fueron más bien magros desde el punto de vista del Derecho, toda vez que el contenido de la propiedad se exacerbó hasta ámbitos que difícilmente le son propios con la propietarización de todos los derechos, y la creación de contradicciones internas en nuestro sistema de bienes que jamás han sido zanjadas debidamente. Tal vez por esto mismo, nuestro objetivo se aleja del tratamiento de los límites de la propiedad desde el punto de vista del interés público, una materia que tiene un fuerte componente de carácter meta-jurídico, pleno de problemas políticos y económicos, para centrarse en los límites que debe observar el derecho de propiedad desde el punto de vista del interés privado, una materia prácticamente abandonada por nuestra doctrina y que, sin embargo, resulta de fundamental importancia atendido el estado de desarrollo de nuestro sistema jurídico y social ${ }^{1}$.

Sin perjuicio de realizar un análisis más detallado, con el objeto de encuadrar el problema, diremos que el dominio consiste básicamente en contar con acciones destinadas a proteger y resguardar el ejercicio de actos posesorios sobre determinados bienes. Dichos actos pueden ser de uso, de goce o de disposición y el propietario es, en principio, libre de realizar los que desee; son los confines del bien los que marcan el límite al ejercicio de dichos actos. Es decir, un sujeto es libre de realizar los actos que desee sobre su bien, pero su actuar se encuentra restringido a dicha entidad sin que pueda ejecutar su voluntad más allá de los límites de la misma. Sin embargo, del ejercicio de actos en lo propio, es decir, dentro de los confines del bien, pueden derivarse consecuencias que se extiendan fuera de los confines de la cosa en cuestión, es decir, emisiones. Cuando estas emisiones penetran en la esfera de un bien

\footnotetext{
${ }^{1}$ En palabras de García Sánchez, Justo, Teoría de la immissio (Oviedo, Universidad de Oviedo, 1999), p. 14: “A medida que evoluciona la sociedad se hace más necesario establecer limitaciones a este derecho [de propiedad] y pasar de un estado de absoluta independencia a otra de coordinación de los respectivos derechos e incluso, en algunos casos, de subordinación".
} 
ajeno podemos hablar de inmisiones, las cuales pueden llegar a tener tal entidad que, de facto, impidan el ejercicio de algunos o incluso de todos los actos posesorios que un propietario pretenda realizar en su bien.

A fin de clarificar la cuestión, pongamos como ejemplo el acto de leer un libro que posiblemente Ud. esté realizando en este mismo momento en su casa. Del mismo no se genera emisión alguna, de manera que su ejercicio no puede ser cuestionado. Sin embargo, supongamos que en lugar de leer un libro, el acto posesorio de uso ejecutado sea tocar la batería. Este acto sí tiene emisiones sonoras evidentes, aunque puede que su casa esté aislada en el campo y, por lo tanto, de dichas emisiones no se derive inmisión alguna. Ahora bien, si Ud. vive en un edificio de departamentos, muy probablemente las emisiones derivadas de su actividad penetren en el inmueble vecino y si, además, son las cuatro de la mañana, lo más seguro es que su vecino no pueda realizar un acto de uso en su casa, el dormir. Si lo que sucede es que ha decidido dar un nuevo uso comercial a su vivienda, digamos establecer un club de jazz, es muy posible que el uso habitacional que su vecino pretende dar a su propia vivienda se vea frustrado. Ahora supongamos que el acto realizado en lo propio sea la refinación de petróleo. De esta actividad, en general, se derivan emisiones que fácilmente se convierten en inmisiones. Estas pueden ser de tal naturaleza que perjudiquen los predios vecinos hasta envenenar la tierra y, por tanto, los hagan inútiles para cualquier actividad productiva, como de hecho ha sucedido en nuestro país. Muchas de estas actividades requieren autorizaciones administrativas, pero éstas no son patentes de corso ${ }^{2}$ para perjudicar libremente al vecino y, por lo demás, estas regulan las relaciones entre un particular y el Estado, más no las relaciones entre particulares, como en el caso. El problema de los límites del dominio en interés privado suele terminar por reducirse a las relaciones de vecindad ${ }^{3}$,

${ }^{2}$ Padial Albás, Adoración - Toldrà Roca, María Dolores, El derecho de propiedad y otros derechos reales en el derecho civil de Cataluña (Valencia, Tirant lo Blanch, 2008), pp. 55-56.

${ }^{3}$ En este sentido JHering, Rudolf von, Jahrbücher für die Dogmatic des heutigen römischen und deutchen Privatrechts (1863), pp. 84-5. Igualmente Pescio, Victorio, Manual de Derecho civil (Santiago, Editorial Jurídica, 1978), p. 327, dice: "Son varias y múltiple las restricciones impuestas al dominio por el Código Civil inspiradas en un sentido de protección del interés privado [...]. Las más conspicuas son las que resultan de la relación de vecindad. Debemos observar, asimismo, que a algunas de ellas el Código les ha atribuido el carácter de servidumbres". En el mismo sentido, podemos citar la opinión de Algarra Prats, Esther, La defensa jurídico-civil frente a humos, olores, ruidos y otras agresiones a la propiedad y a la persona (Madrid, McGraw-Hill, 1995), p. 12: "Sin perjuicio de ulteriores precisiones al respecto, he de señalar ahora que las relaciones de vecindad se enmarcan jurídicamente en el ámbito del derecho de propiedad, y más concretamente, de la propiedad inmobiliaria”. 
aunque no es necesariamente el único ámbito en que el ejercicio de actos en lo propio puede afectar lo ajeno. Lo que sucede es que los bienes muebles, al ser susceptibles de traslado, suelen movilizarse para evitar las consecuencias perniciosas cuyo uso pueda ocasionar, mientras que la naturaleza inmóvil de los bienes raíces obliga a soportar las consecuencias nocivas del comportamiento del vecino en su propio predio.

Si la propiedad consiste en que el Derecho dota al dueño de acciones para que resguarde el ejercicio de actos posesorios sobre el bien ¿existirán acciones en nuestro Derecho que sean aplicables a tal caso? En nuestro país, usualmente estos problemas toman vías administrativas, no siempre seguras, puesto que el Derecho administrativo rige las relaciones entre el Estado y los particulares, no entre particulares por lo que buena parte de los problemas que se generan, cuando no se requiere de autorización administrativa, simplemente quedan fuera de su ámbito. Otra forma de enfrentarlo es por la vía constitucional a través del recurso de protección, de resultados inciertos, donde la indemnización por los perjuicios sufridos no tiene cabida y con un plazo muy corto para su ejercicio. Incluso se ha tentado el uso de la responsabilidad extracontractual para ello, con los obvios limitantes de la prueba de la culpa y el dolo, pero amén de ello, el problema es que en buena parte de los casos lo que se busca no es la indemnización, sino, más bien, que se detenga la inmisión, pues los perjuicios son difícilmente cuantificables. Nosotros, al respecto, creemos que el problema tiene dos soluciones que intentaremos demostrar a lo largo de este artículo. La primera es una salida cautelar ligada a las acciones posesorias, tan poco usadas en nuestro medio, que expresamente cubren los casos de inmisiones en nuestro Código Civil. La segunda se encuentra relacionada con la acción negatoria, que no está contemplada expresamente en nuestra doctrina, pero que se deduce necesariamente de la dogmática de nuestro Derecho.

\section{LA DEFINICIÓN DE PROPIEDAD Y LOS LÍMITES EN EL DERECHO AJENO}

Naturalmente, en una investigación de esta naturaleza nuestro punto de partida no puede ser otro que la definición de dominio que entrega nuestro propio Código Civil. Al respecto, en su artículo 582 inciso $1^{\circ}$ reza: "El dominio (que se llama también propiedad) es el derecho real en una cosa corporal, para gozar y disponer de ella arbitrariamente; no siendo contra la ley o contra derecho ajeno"

A pesar que la doctrina nacional ha afirmado que se trata de una transcripción de la definición de propiedad del Código Civil francés ${ }^{4}$, en verdad la

\footnotetext{
${ }^{4}$ Así, Alessandri Rodríguez, Arturo, De los bienes (Santiago, Zamorano y Ca-
} 
disposición es sutilmente diferente. Al efecto, la definición del artículo 544 CCFr. dice: "La propiedad es el derecho de gozar y disponer de las cosas de la manera más absoluta, poder del que no puede hacerse un uso probibido por las leyes o por los reglamentos"

Aunque formalmente son similares, con la sola lectura saltan a la vista algunas diferencias que tienen interés dogmático. En primer término, en la versión francesa no aparece la mención expresa de las cosas corporales, la expresión "de la manera más absoluta" ha sido reemplazada por la voz "arbitrariamente", pero, lo más notable desde nuestra perspectiva es que la limitación reglamentaria del uso que puede hacerse de la propiedad ha sido reemplazada por una limitación en interés del derecho ajeno, que se encuentra preñada de consecuencias dogmáticas.

En verdad, durante el siglo XIX lo más común a la hora de definir el dominio era simplemente copiar la definición francesa ${ }^{6}$, puesto que se creía vulgarmente que era la transcripción de cierta definición romana de propiedad ${ }^{7}$, la cual, por cierto, nunca existió ${ }^{8}$. Así, se solía imputar la existencia

perán, 1937), p. 25, señala: “[...] el artículo 582, que no hace sino reproducir el concepto individualista extremo del Código de Napoleón”. Esta idea es luego desarrollada por Lira Urquieta, Pedro, El Código Civil y el nuevo Derecho (Santiago, Nascimento, 1944), p. 166, quien expresa: "Para nuestro intento nos basta con remontarnos al Código Napoleón, fuente primera de nuestro Código Civil y modelo acabado del régimen individualista y libertario imperante en esa época".

5 "La propriété est le droit de jouir et disposer des choses de la manière la plus absolue, pourvu qu'on n'en fasse pas un usage prohibépar les lois ou par les règlemens"

${ }^{6}$ Así lo hacen el artículo 439 del Código sardo de 1837; el artículo 625 del Código de Holanda de 1838; el artículo 240 del Código Civil de Lucerna de 1839; el artículo 422 del Código Civil de Bolivia de 1843; el artículo 464 de Código de Fribourg de 1850; el artículo 170 del Código Civil danés de 1850; el artículo 591 del proyecto de García Goyena de 1851; el artículo 380 del Código de Valais de 1853; el artículo 392 del Código de Neuchatel de 1854 y el artículo 436 del Código Civil italiano de 1865. La única variación, aparte del Código de Bello, que detectamos en dichos cuerpos está en el Código de Berna, cuyo libro sobre las cosas se publica en 1827 y que establece en su artículo 377: "La propiété est le droit de disposer arvitrairement et exclusivement de la substance et des fruits d'une chose en se conformant aux lois".

${ }^{7}$ Véase: Montes, Vicente, La propiedad privada en el sistema del Derecho civil contemporáneo (Madrid, Civitas, 1980), p. 62 n. 83 que señala: "Durante mucho tiempo se pensó que la definición del artículo 544 (del Code) era una traducción de la definición que las leyes romanas daban de la propiedad." La tradición escolástica creyó que esta era la definición de propiedad de los romanos. Añade en p. 242: "En consecuencia, el poder del propietario no es absoluto, ni en el sentido de que predomine el arbitrio del propietario o de que falten limitaciones, ni en el sentido de que la titularidad dominical se vea correspondida por una suerte de obligación o deber de respeto de los demás ciudadanos. Ello operaría una transposición indebida al plan de las situaciones jurídicas subjetivas, de un carácter que puede considerarse propio de la norma en cuanto regla de comportamiento: alterum non laedere".

${ }^{8}$ Basta para ello simplemente ver el comentario al artículo 391 de las concordan- 
de tal definición a cierta constitución imperial contenida en el Codex de Justiniano que en verdad trataba del mandato\%. El precepto simplemente intentaba diferenciar las facultades que un mandatario tiene respecto a las cosas objeto del encargo respecto al dueño del negocio, quien es "es moderador y árbitro [...] de sus propias cosas". En verdad no es una definición de dominio lo que contiene, pero sí las primeras notas de de lo que un día constituirá dicha definición. Estas palabras, y especialmente la voz arbiter con que define el uso que el dueño puede hacer de sus cosas, se puso en contacto con la idea de libertad del dueño. En efecto, el molde sobre el que está compuesta la definición de propiedad es la definición de libertad contenida en Dig. 1,5,4,1 ${ }^{10}$ (Florentino, lib. IX de sus Institutiones): "La libertad es la facultad natural de uno para hacer lo que desee, salvo si ello está prohibido por la fuerza o el derecho".

En efecto, de sólo leer la definición de libertad vemos en ella los elementos estructurales a partir de los cuales se construye la idea de propiedad. Se la califica como una facultad, se señala que sirve para hacer lo que se desee y se le dan dos límites, el derecho y la fuerza. Tratándose de la libertad, esto tiene sentido, toda vez que, estrictamente hablando, la libertad no está limitada al plano jurídico, sino que tiene también una dimensión fáctica; así, privado de libertad se encuentran tanto el secuestrado y como el condenado por sentencia judicial. En cuanto al dominio, en cambio, este es un derecho y, por tanto, los aspectos fácticos del mismo se encuentran disociados de los aspectos jurídicos. El dominio es sólo derecho, mientras que su lado material es la posesión, de manera que los límites del dominio deberán ser necesaria-

cias de García Goyena, Florencio, Concordancia motivos y comentarios del Código Civil español (Madrid, Imprenta de la Sociedad Tipográfico, 1852), pp. 351-352. El autor cree sinceramente que su definición está tomada directamente de Roma. En dicho artículo del proyecto se definía el dominio simplemente traduciendo la definición francesa.

${ }^{9}$ Cod. Iust. 4,35,21: "Imperator Constantinus $A$. Volusiano pp. In re mandata non pecuniae solum, cuius est certissimum mandati iudicium, verum etiam existimationis periculum est. Nam suae quidem quisque rei moderator atque arbiter non omnia negotia, sed pleraque ex proprio animo facit: aliena vero negotia exacto officio geruntur nec quicquam in eorum administratione neglectum ac declinatum culpa vacuum est" [a. 313-315?] ("El emperador Constantino, Augusto, a Volusiano, prefecto del pretorio. Tratándose del mandato hay el riesgo no solamente del dinero, para el cual hay la acción certísima de mandato, sino también de la estimación. Porque a la verdad, es moderador y árbitro cada cual de sus propias cosas, hace por su propia voluntad no todos sus negocios, sino por su mayor parte. Pero los negocios ajenos se desempeñan habiéndose cumplido el cargo, y nada que en la administración de los mismos se haya descuidado y dejado está exento de culpa").

10. "Libertas est naturalis facultas eius quod cuique facere libet, nisi si quid ui aut iure probibetur". 
mente jurídicos. Al respecto, el comentarista Bártolo de Sasoferrato discutía la opinión del glosador Azón respecto a que la posesión tenía, de acuerdo a éste último, una consistencia jurídica ${ }^{11} \mathrm{y}$, en su argumentación, mientras comentaba un fragmento del Digesto que distingue entre propiedad y posesión ${ }^{12}$, creo la definición más usada de dominio: "dominio es el derecho en cosa corporal para disponer de ella, salvo que la ley lo prohíba"13. La opinión unánime de la doctrina es que esta sería la primera definición del dominio en la Historia del Derecho ${ }^{14}$, aunque esto no es exactamente cierto. Existe una definición bastante anterior que expresa la misma síntesis de ideas. Esta es la definición de propiedad que contienen la partículo III, título 28 ley $1^{a}: b$ "Señorío es poder que ome ha en su cosa de fazer della, e enella lo que quisiere: segun Dios e segund fuero".

Esta se encuentra sistemáticamente bastante cerca de nuestra definición actual de dominio, toda vez que lo define expresamente como un poder y le otorga dos límites al mismo, el derecho emanado de Dios y la legislación humana, que se expresa con la idea de fuero. Se mantiene, tal vez por un deseo de armonía con la idea de libertad, la existencia de un límite doble del dominio, aunque se reemplaza la limitación fáctica de la limitación jurídica. Por lo demás, las Partidas mantienen una distinción neta entre propiedad y posesión que incluso se encuentra aclarada algo más adelante en la partículo VII, de una manera acorde con el pensamiento que más tarde expresará Bártolo $^{15}$. Esto hace pensar en un origen común, aunque, de momento, faltan los textos intermedios que permitan conectar ambas definiciones.

Dentro de las Partidas, una vez tratado el dominio se pasa a exponer lo relativo a las servidumbres (partículo III, 3 , tít. $3^{\circ}$ ) y, en el acápite siguiente,

${ }^{11}$ Bartolus, Ad Dig. Novum comm. prima pars, pp. 160-161.

${ }^{12}$ Dig. 41,2,17,1 (Ulpianus, 76 ad ed.): "Differentia inter dominium et possessionem haec est, quod dominium nibilo minus eius manet, qui dominus esse non vult, possessio autem recedit, ut quisque constituit nolle possidere. si quis igitur ea mente possessionem tradidit, ut postea ei restituatur, desinit possidere".

${ }^{13}$ Bartolus, Ad Dig. Novum comm. prima pars, p. 185: "dominium est ius de re coporali perfecte disponendi, nisi lex prohibeatur".

${ }^{14}$ Véase: Piccinelli, Ferdinando, Studi e ricerche intorno alla definizione dominium est ius utendi et abutendi re sua quatenus iuris ratio patitur (reimpresión Napoli, Jovene, 1980), pp. 42 ss. Entre los autores más recientes y con bibliografía más abultada que afirman exactamente esto encontramos a RüFnER, Thomas, The Roman Concept of Ownership and the Medieval Doctrine of Dominium Utile, en CAIRns, John W. - Du Plessis, Paul J. (editores), The Creation of Ius Commune. From Casus to Regula (Edinburgh University Press, 2010), pp. 127-142.

${ }^{15}$ Además, en part. VII, tít. $33^{\circ}$, ley $10^{a}$ se da otra definición, un poco menos interesante para nuestros propósitos: "Otrosi dezimos que propiedad es el señorio de la cosa: e posesion es la tenecia della". 
de forma sistemáticamente similar a nuestro Código Civil, se tratan las acciones posesorias (partículo III, tít. $32^{\circ}$ ). Es durante el tratamiento de éstas que encontraremos la primera referencia al derecho ajeno respecto a la definición de dominio. A propósito de la denuncia de obra nueva el legislador alfonsino prohíbe una serie de actos que pueden realizarse en lo propio y cuyas consecuencias, al proyectarse en el ámbito de los bienes vecinos, turban su posesión, como la construcción de depósitos de agua, canales u obras que estanquen las aguas lluvias. A este respecto expresa partículo III, tít. $32^{\circ}$, ley 13a: "Ca segund que dixeron los sabios antiguos maguer el ome aya poder de fazer en lo suyo lo que quisiere. Pero deue lo fazer de manera que non faga daño, nin tuerto a otro".

El principio es bastante claro, cada cual puede hacer en lo propio lo que desee, siempre que las consecuencias de sus actos no menoscaben lo ajeno, es decir, no siendo contra derecho ajeno. En la glosa a las mismas, Gregorio López, el principal comentarista de las Partidas y cuyas glosas pasaron a formar parte de una suerte de edición oficial de las mismas que se utilizó en todos los dominios castellanos hasta la codificación, explica la ley haciendo referencia a un fragmento romano del jurista Aristón que se encuentra en el Digesto y que analizaremos en repetidas oportunidades, Dig. 8,5,8,5, donde efectivamente aparece el dictum que las Partidas traducen. Sin perjuicio de darle un tratamiento detallado en otro lugar ${ }^{16}$, de momento nos basta con describir brevísimamente el caso: Un particular llamado Cerelio Vital arrienda un edificio a la ciudad de Minturno donde instala una fábrica de quesos. El resultado es emitir una gran cantidad de pesados humos molestan a los vecinos de los predios superiores. Consultado al respecto, el jurista responde que si no hay servidumbre, no tiene derecho a inmitir humos en los edificios superiores y que, a más de la acción negatoria, puede interponerse en su contra el interdicto uti possidetis, es decir, el antecedente romano de nuestra querella de amparo. Es en este contexto que expresa "in suo enim alii hactenus facere licet, quatenus nibil in alienum immittat", es decir, cada uno puede hacer en lo suyo lo que desee, siempre que no invada lo ajeno. El dictum de las Partidas está tomado directamente del fragmento romano.

En esta brevísima historia de la coletilla del la interdicción de uso en contra del derecho ajeno que contiene la definición de propiedad, nos toca señalar que el fragmento del que hablamos se encuentra a propósito de las servidumbres dentro de la sistemática de Digesto. En este contexto, cuando, producto de la labor de los comentaristas, algunos decenios después de la

${ }^{16} \mathrm{Al}$ respecto, véase: Amunátegui Perelló, Carlos Felipe, "No siendo contra derecho ajeno": hacia la formulación de una teoría de las inmisiones en nuestro Código Civil, en Revista Chilena de Derecho, 36 (2009) 3, pp. 505-525. 
redacción de las Partidas, se sistematizaron las servidumbres en el famoso árbol de las servidumbres ${ }^{17}$, el problema de las relaciones de vecindad quedó parcialmente relegado a este tema y es ahí en donde son recogidos y tratados estos problemas por Domat ${ }^{18}$. Puesto que en el acápite siguiente nos ocuparemos de este fenómeno, de momento nos interesa volver a la definición de propiedad y la integración de la interdicción de uso en contra del derecho ajeno. Aparentemente, el mérito de haber integrado ambas fórmulas pertenece a Pothier, quien en su Traitè $d u$ droit de domaine de la proprietè define el dominio en los siguientes términos ${ }^{19}$ : "[...] el derecho de disponer libremente de una cosa, sin menoscabar, con todo el derecho de otro ni atentar contra las leyes. Jus de re libere disponendi o jus utendi et abutendi".

Para la explicación exacta del significado de la limitación en razón del derecho ajeno, Pothier nos reenvía, inesperadamente, a su tratado de la socie$\mathrm{dad}$, donde ha establecido un cuasicontrato de vecindad ${ }^{20}$ :"Hemos definido el derecho de propiedad, el derecho de disponer libremente de una cosa; y añadiendo sin menoscabar con todo el derecho de otro [...] [se entiende aquí] el derecho de los propietarios y posesores de fincas lindantes"

El problema para Pothier es que, desde su perspectiva, de la vecindad surgen obligaciones entre los dueños de los predios vecinos que difícilmente pueden encuadrarse como servidumbres. A fin de evitar esta dificultad, y puesto que la vecindad es un hecho voluntario, no consensual y lícito, imagina un cuasicontrato del cual nacerían obligaciones recíprocas entre las partes ${ }^{21}$.

${ }^{17}$ Éste parece ser creación del mismo Bártolo. Véase: BIONDI, Biondo, Le serivtù prediali nel diritto romano (Milano, Giuffrè, 1969), p. 75; y BARToli a SaxoferraTO, In primam Digesti Veteris pertem commentaria (Augusta Taurinorum, Nicolau Bevilaquam, 1574, reimpresión de A.J.B. Sirks, Maastricht, 2004), 182v $=364$.

${ }^{18}$ Específicamente en Domat, Jean, Oeuvres complètes (Paris, Alex-Gobelet, 1835), IV, p. 194.

${ }^{19}$ Pothier, Robert-Joseph, Traité du droit de domaine de propriété, en Ouvres (Paris, Pichon-Béchet, 1827), VII, p. 114 : "le droit de disposer á son gré d'une chose sans donner neanmoins atteinte au droit d'autroui, ni aux lois; ius de re libere disponendi, ou ius utendi et abutendi". La traducción la tomamos de Pothier, R. L., Obras Completas. Tratado del derecho de dominio de la propiedad (Barcelona, Imprenta de la viuda e hijos de J. Subirana, 1882), VII, p. 8. Sobre la importancia de Pothier para construir una noción abstracta de dominio, véase: Grossi, Paolo, Percezioni medievali e moderne dei diritti reali, en Il dominio e le cose (Milano, Giuffrè, 1992), pp. 385 ss.

${ }^{20}$ Pothier, Robert-Joseph, Obras Completas, Tratado, cit. (n. 19), VII, p. 14. En su versión francesa, Oeuvres, Traité, cit. (p. 19), p. 118, dice: "Nous avons défini le droit de propiété, le droit de disposer à son gré d'una chose, et nous avons ajouté, sans donner néanmoisatteinte au droit d'autrui [...] cela s'entend aussi du droit des propiétaires et possesseurs de héritages voisins".

${ }^{21}$ Así, expresa en Tratado del contrato de sociedad (Barcelona, Imprenta y Litografía de J. Roger, 1841), p. 103 parágrafo 230: "La contigüidad de heredades es un cuasi 
Esta visión, sin embargo, implica distintos problemas a nivel teórico, como por ejemplo, la ausencia de sujetos fijos en las obligaciones que ambulan con la titularidad del predio y la inexistencia de un objeto determinado de la misma. Es por ello que su enfoque teórico fue generalmente rechazado y no fue recogido en la codificación francesa. Lo que sí quedó, en todo caso, fue la idea de la limitación de la propiedad en razón de los intereses de los vecinos.

La Revolución Francesa fue un elemento altamente innovador en las relaciones de vecindad. Éstas, bajo el Antiguo Régimen, representaban un complejo conjunto de relaciones entre los vecinos que pueden considerarse solidaridades forzosas ${ }^{22}$. Provenientes de la Edad Media y con un fuerte componente germánico, las relaciones de vecindad abarcaban en el viejo entramado consuetudinario francés mucho más que los simples deberes de abstinencia de inmitir establecidos desde la óptica del Derecho romano. Implicaban deberes en torno a la administración de justicia vecinal, funciones de policía, tutela, derechos en cosas comunes y derechos de uso inocuo de los bienes del vecino. Todo este complejo entramado fue borrado de un plumazo por el espíritu revolucionario que veía en el hombre solamente a un individuo y no a un miembro de una comunidad. Las relaciones de vecindad son extirpadas del Código, salvo dentro de la estrecha perspectiva de las servidumbres legales y, como consecuencia, de la definición de dominio donde son reemplazadas por los reglamentos. De esta manera es que el Code Napoléon, buscando dar certeza al contenido de las relaciones de vecindad estableció su propio doble límite, la ley, como tradicionalmente se había expresado, y los reglamentos, ya que estos en su calidad de normas de policía debían delimitar las relaciones de vecindad. Los límites establecidos por la ley pueden ser en interés público o privado, pero lo importante es que el contenido de dichas limitaciones ha de estar fijado en la ley, sea en forma de expropiación, sea como servidumbres legales o como permisos administrativos ${ }^{23}$.

contrato que forma obligaciones recíprocas entre vecinos, es decir, entre los dueños o poseedores de las heredades limítrofes. La principal de estas obligaciones es la que concierne al acotamiento de las heredades, del cual hablaremos en el primer artículo. Referimos en el segundo las demás obligaciones que esta contigüidad lleva consigo".

${ }^{22} \mathrm{Al}$ respecto, véase: DAvid, Jacqueline, Les solidarités juridiques de voisinage, de l'ancien Droit à la codification, en Revue Historique de Droit Français et Étranger, 72 (1994) 3, pp. 333-366.

${ }^{23}$ Así se entendió el precepto desde la primera exégesis. Véase, por ejemplo, el comentario de Delvincourt, C., Cours de Code Civil (Paris, Videcoq, 1834), I, p. 149 al respecto: "[...] parce que l'homme jouissant des avantages de la société, doit, de son côté. Accomplir les obligations qu'elle lui impose, au nombre desquelles est celle de ne point faire de sa chose un usage contraire aux dispositions établies par les lois ou les règlements, dans l'intérêt, soit du public, soit des particuliers". 
La definición del Code, sin embargo, no estuvo exenta de polémica. En primer lugar se criticó esa manera de ejercer la propiedad "de la manera más absoluta”, una frase que intentaba simplemente diferenciar la propiedad de otros derechos reales de carácter más limitado y poner de manifiesto al exclusividad de la misma ${ }^{24}$. Se dijo que existía una contradicción lógica entre la afirmación el carácter absoluto de la propiedad y el establecimiento, a reglón seguido, de límites ${ }^{25}$. También se ha estimado que abre un espacio al abuso en la utilización de los bienes ${ }^{26}$ e incluso que la visión burguesa sobre la propiedad que contempla no sería acorde con el sentido social que este derecho tiene desde una perspectiva moderna ${ }^{27}$.

Estas críticas, que nos parecen injustas respecto al precepto francés, son del todo inadmisibles en cuanto a la definición de Bello que manifiestamente ha cambiado los términos de la misma, recibiendo una concepción de la propiedad mucho más limitada desde la tradición de Pothier y las Partidas. Al respecto, la primera redacción de la definición de propiedad se encuentra en el artículo 686 del Proyecto de Código Civil de 185328: "El dominio (que sellama también propiedad) es el derecho real en una cosa corporal, para gozar i disponer de ella a nuestro arbitrio, no siendo contra lei o contra derecho ajeno"

La única diferencia con la redacción definitiva del artículo 582 es aquel "a nuestro arbitrio" que será reemplazado por "arbitrariamente” en el artículo 682 del llamado "Proyecto Inédito" ${ }^{29}$. No obstante ser tal vez más precisa la

${ }^{24}$ De Martino, Francesco, Del possesso, en Comentario del códice civile. Libro terzo. Della proprietá (Bologna, Nicola Zanichelli Editore, 1970), p. 147.

${ }^{25}$ Planiol, Marcel, Traité élémentaire de Droit civil (Paris, Librairie Générale de Droit \& Jurisprudence, 1915), I, p. 720. Esta opinión se ha repetido respecto a nuestra propia definición. Véase: Pescio, V., Manual, cit. (n. 3), p. 274 n. 3.

${ }^{26}$ Lázaro Guillamón, Carmen, La acción negatoria (Valencia, Tirant lo Blanch, 2007), p. 11 "Es falaz la calificación de la propiedad como derecho absoluto, son muchas las circunstancias que la definen como derecho directamente vinculado a la comunidad a la que sirve $[. .]$.$" .$

${ }^{27}$ Así, Pescio, V., Manual, cit. (n. 3), p. 294, señala: "Sin embargo, en el día y a consecuencia de la evolución que ha experimentado el derecho de propiedad, nada es más discutible, relativo y hasta ilusorio que el carácter absoluto que se le atribuye en su concepción clásica. Orgánicamente, lo limita la ley y el derecho ajeno”. Por su parte, Alessandri Rodríguez, A., De los bienes, cit. (n. 4), p. 25, dice otro tanto: “[...] el artículo 582, que no hace sino reproducir el concepto individualista extremo del Código de Napoleón".

${ }^{28}$ Bello, Andrés, Obras completas (Santiago, Impreso por Pedro G. Ramírez, 1888), XII.

${ }^{29}$ BeLlo, Andrés, Obras completas (Santiago, Nascimento, 1952), III. El llamado "Proyecto Inédito" es una invención de Amunátegui Reyes que, tomando cuatro ejemplares del "Proyecto de 1853" que contenían notas de distintos miembros de la Comisión Revisora del Proyecto de Código Civil, los editó conjuntamente con las variantes 
redacción original y mejor concordante con el arbiter del Codex justinianeo, pareció poco elegante usar una primera persona plural en una definición ${ }^{30}$.

Hasta aquí podemos concluir, observando la historia de la tradición textual de la definición de dominio, que Bello tomó la definición antes de Pothier que de la codificación francesa ${ }^{31}$. Su visión del ejercicio de la propiedad como limitado por el derecho ajeno tiene su origen en una doble conjunción, por una parte la tradición castellana de las Partidas que establece que las cosas no pueden usarse de manera que dañen a otro, y por otra las relaciones de vecindad a que hace referencia la limitación de ejercicio de Pothier.

No obstante, dentro de la sistemática del Código no quedó consagrada la teoría de Pothier sobre el cuasicontrato de vecindad. En su lugar, Andrés Bello optó por dos caminos distintos para las relaciones de vecindad. De una parte, recogió la estructura del Code, que trata las relaciones de vecindad entre las servidumbres legales y por otra, siguiendo a las Partidas, las fijó entre las acciones posesorias. Es de destacar que en materia de acciones posesorias el Código de Bello es manifiestamente original, toda vez que la codificación francesa no las trata, por lo que la inmensa mayoría de los códigos civiles de la primera parte del siglo XIX tampoco lo hacen. Al parecer, en esta materia Bello siguió directamente la tradición castellana representada por las Partidas y los juristas castellanos del siglo XVIII ${ }^{32}$. De aquí que en nuestro Código se produzcan algunos fenómenos curiosos, como la reiteración del tratamiento de algunos casos de conflictos entre vecinos por el uso que uno de ellos hace en lo propio en sede de servidumbres legales y en sede posesoria. Así, por ejemplo, los artículos 856 y 941 parecen tratar exactamente el mismo problema y derivar del mismo conjunto de casos romanos, tratándose el tema en dos sedes diversas, como veremos algo más adelante.

No obstante, no debe confundirse la limitación de la propiedad en razón

que cada uno de ellos mostraba. Esta edición se realiza por primera vez en las Obras completas de Andrés Bello, aunque las notas mismas no pertenecen a Bello exclusivamente.

${ }^{30}$ Claro Solar, Luis, Explicaciones de Derecho Civil chileno y comparado. De los Bienes (Santiago, Imprenta Cervantes, 1930), I, p. 334, n. 20.

${ }^{31}$ En contra: Pescio, V., Manual, cit. (n. 3), III, p. 274; Lira, Pedro, El Código Civil y el nuevo Derecho (Santiago, Nascimento, 1944), p. 166; Vodanovic, Antonio, Derecho Civil (Santiago, Nascimento, 1940), p. 230; Alessandri, Arturo, De los Bienes, cit. (n. 4), p. 25, entre otros.

${ }^{32}$ En específico el título parece seguir muy de cerca al jurista Juan Sala, cuya obra Ilustración del Derecho español aparece citada a propósito de las mismas y que, al compararlas, presentan una gran cercanía. $\mathrm{Al}$ respecto hemos tratado el tema con cierto detalle en Inmisiones y querella de amparo. Contribución a la historia dogmática de un caso de responsabilidad objetiva, en Libro de amigos dedicado al profesor Italo Merello (Valparaíso, Ediciones Universitarias de Valparaíso, 2011), pp. 23-31. 
del derecho ajeno con las meras servidumbres legales. En primer término, porque éstas son simplemente una manifestación particular de las relaciones de vecindad, mientras que la interdicción de uso en contra del derecho ajeno tiene, evidentemente, un alcance dogmático mayor que abarca también la teoría del abuso del derecho. En segundo término, las servidumbres legales son un límite establecido por la ley al ejercicio de la propiedad, por lo que sistemáticamente debe encuadrarse dentro del primer término del binomio de restricciones a la misma. En pocas palabras, la ley establece las servidumbres legales y, por tanto, están dentro de los usos prohibidos por la ley. Finalmente, las servidumbres legales pueden estar establecidas en función de un interés público o privado, de manera que malamente pueden coincidir con el derecho ajeno, que es eminentemente un interés de carácter particular ${ }^{33}$. De momento, a fin de clarificar el problema de los límites de la propiedad, nos corresponde tratar las llamadas servidumbres legales, que constituyen un límite legal de la propiedad y una primera sede donde el problema de las relaciones de vecindad se trata.

\section{SERVIDUMBRES LEGALES}

El Código Civil, siguiendo al Código francés, ha definido las servidumbres como un gravamen impuesto sobre un predio en utilidad de otro predio de distinto dueño (artículo 820) ${ }^{34}$. A continuación, luego de tratar algunas reglas generales relativas a las servidumbres, pasa clasificarlas en naturales, legales y voluntarias (artículo 831), siendo ésta categorización la que dirigirá la sistemática del mismo en su tratamiento del tema. Esta definición, sin embargo, es del todo extravagante dentro de la obra de Bello. En primer término, define las servidumbres como una carga y no como un derecho, a diferencia de todos los demás derechos reales. Por lo demás, se aparta de otras definiciones que el mismo Bello había dado de servidumbres con anterioridad. Así, en sus Instituciones de Derecho romano, expresa: "Se llama servidumbre el derecho constituido sobre una cosa ajena, por el cual es

${ }^{33}$ En efecto, el mismo Código Civil, en su artículo 839, se preocupa de señalar que las servidumbres pueden obedecer a un interés público o privado: "Las servidumbres legales son relativas al uso público, o a la utilidad de los particulares./ Las servidumbres legales relativas al uso público son:/ El uso de las riberas en cuanto necesario para la navegación o flote, que se regirá por el Código de Aguas; Y las demás determinadas por los reglamentos u ordenanzas respectivas".

${ }^{34}$ Compárese con el correspondiente artículo 637 del Code: "Une servitude est une charge imposée sur un héritage pour l'usage et l'utilité d'un héritage appartenant à un autre propriétaire". 
obligado el dueño a sufrir o no hacer algo en ella, para que esto resulte en beneficio a otra persona o cosa" ${ }^{35}$.

Esta se corresponde con la traducción literal de la definición de servidumbre de Heineccius ${ }^{36} \mathrm{y}$, al igual que aquéllas que entrega el Código respecto de todos los demás derechos reales, constituye una definición en positivo.

Se aparta también ostensiblemente de la tradición hispana, toda vez que las Partidas definían las servidumbres en otros términos ${ }^{37}$, como también de la tradición medieval ${ }^{38}$ e incluso de los humanistas del siglo $\mathrm{XVI}^{39}$ y de los racionalistas de los siglos XVII y XVIII ${ }^{40}$.

La definición es un aporte del impulso codificador francés, que aparece por primera vez en el proyecto Cambacèrés de 1793. Parece haber sido tomada por la tradición jurisprudencial francesa de la traducción latina de la paráfrasis de Teófilo, una fuente algo extraña, pero que terminó por primar en la generalidad de los códigos civiles del mundo gracias a la influencia francesa ${ }^{41}$.

${ }^{35}$ Bello, Andrés, Instituciones de Derecho romano (Santiago, Imprenta Nacional, 1878), p. 61.

${ }^{36}$ Heineccius, Ioann. Christian, Institutiones iuris civilis (Gottingae, Dieterich, 1800), p.185: "servitus est ius in re aliena constitutum, quo dominus in re sua aliquid pati, vel non facere tenetur in alterius personae reive utilitatem"

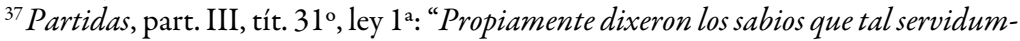
bre como esta es derecho e uso que ome ha en los edificios, o en las heredades agenas para servirse dellas a pro de las suyas".

${ }^{38}$ La definición usual utilizada en el Medioevo es obra de BARToli a SAXofeRRATO, In primam Digesti Veteris pertem commentaria (Augusta Taurinorum, Nicolau Bevilaquam, 1574, reimpresión de A.J.B. Sirks, reimp. Maastricht, 2004), p. 182v = 364, quien definía las servidumbres reales como: "quoddam ius praedio inherens, et ipsus utilitatem re spiciens, et alterius praedius ius sive libertatem diminuens"

${ }^{39}$ Así, por ejemplo, Donellus escribe: "Ea est [servitus] quae alieno praedio imposita ad vicini alicujus praedii solius ususm, eumque perpetuum constituta est" [DONELLI, Hugonis, Opera Omnia. Comentariorum de iure civili (Maceratae, Osualdi Hilligeri, 1839), III, pp. 226].

${ }^{40}$ Así, Pothier, R.-J., Cotume d'Orléans, en CEuvres (Paris, Videcoq, 1845), I, p. 312, señala a este respecto: "Le droit de servitude est le droit de se servir de la chose d'autrui à quelque usage, ou d'en interdire quelque usage au propiétarire ou possesseur. Jus faciendi aut prohibendi aliquid in alieno".

${ }^{41}$ Específicamente, y como era de esperarse, un jurista del humanismo recoge este concepto; asì, JANI A CoSTA, Praelectiones ad illustriores quosdam títulos locaque selecta iuris civilis (Lugduni Batavorum, B. Voorda, 1723, p. 22, citando a Teófilo, expesar "Est igitur servitus, ut recte Theophilus noster, jus quoddam certis modis constitutum, quod effcit, ut vicinus vicini onera sustineat". Para más detalles sobre el proceso de transmisión textual, véase: Falcone, Giuseppe, Note historique sur la définition législative de la servitude (article 637 Code Napoléon - article 1027 Cod. Civ. It.), en Revue Historique de Droit Français et Étranger, 79 (2001) 1, pp. 13-30. 
Algo similar ocurre con la clasificación de las servidumbres en naturales, legales y convencionales que guía el tratamiento del tema en nuestro Código y que fue tomada también ostensiblemente del Code Napoléon. En efecto, ésta parece una innovación dentro del tratamiento tradicional que la jurisprudencia hispana había dado al tema ${ }^{42}$. Sin embargo, el concepto de servidumbres legales no parece muy feliz, toda vez que ha sido objeto de una crítica más bien acerva. En efecto, algunas de las servidumbres legales no parecen adaptarse a la categoría englobada por la definición. Así, en las servidumbres de cerramiento o de medianería difícilmente podría verse un fundo sirviente y otro dominante, toda vez que son derechos y obligaciones que afectan por igual a ambos predios $^{43}$. Este tipo de servidumbres legales parecen ser más bien delimitaciones legales de la propiedad, puesto que su función primordial es establecer el ámbito preciso en que este derecho se ejercerá sobre un inmueble. Configuran el contenido de la misma, al permitir la delimitación precisa del bien. De ahí que experimenten un carácter de igualdad que está completamente excluido de las servidumbres propiamente tales ${ }^{44}$, donde el

${ }^{42}$ Tanto es así que García Goyena, Florencio, Concordancias motivos y comentarios del Código Civil español (Madrid, Sociedad tipográfico editorial, 1852), I, p. 420., al incorporar tal categoría en su Proyecto de Código Civil, se preocupa de aclarar: "El Derecho romano y patrio no comprendieron estos gravámenes entre las servidumbres, $y$ les dedicaron títulos separados, como se ve en los tres primeros del libro 39, y en casi todos del 43 del Digesto, y en el titulo 32, Partida 3, sobre las labores nuevas".

${ }^{43}$ Claro Solar, Luis, Explicaciones de derecho civil y comparado. De los bienes (Santiago, Nascimento, 1935), IX, 4, p. 60, expresa al respecto que: "las servidumbres que se derivan de la situación natural de los lugares no se diferencias de las que la ley impone, y porque unas y otras no son, en realidad, verdaderas servidumbres, sino prohibiciones o condiciones establecidas por la ley o por las ordenanzas o reglamentos inherentes al derecho de propiedad [...]". Específicamente respecto a la medianería, RivERA Serrano, Manuel, Servidumbre de medianería (Granada, Comares, 1999), p. 2, señala: "La sistemática utilizada evidencia que el Código conceptúa la medianería como una servidumbre. A pesar de su catalogación, su naturaleza es y ha sido controvertida por cuanto en la medianería no cabe señalar cuál es el predio dominante y cual el sirviente [...]. Algunos autores entienden que se la debe concebir como una modalidad especial dentro de esta clase de derechos reales, calificándola de servidumbre recíproca, por ser cada predio dominante y a la vez sirviente. Otros [...] como una comunidad especial". Más enfáticamente expone LlÁcer MatacÁs, M. R., Relaciones de vecindad, en VV. AA., Tratado de servidumbres (Navarra, Aranzadi, 2002), p. 797: "No consideramos oportuno utilizar la expresión 'servidumbres legales', sino que vamos a referirnos a los límites de la propiedad, que se articulan en torno a las relaciones de vecindad de acuerdo con la función social de la propiedad (33.1 CE) [...]. La ley 13/1990 presenta el mérito de haber sistematizado, bajo 'relaciones de vecindad' las mal llamadas servidumbres legales que en el Código Civil suelen aparecer dispersas".

${ }^{44}$ Biondi, Biondo, La categoria romana delle "servitutes" (Milano, Vita e Pensiero, 1936), p. 19. 
ejercicio de actos posesorios sobre el predio sirviente se supedita al derecho que lo grava respecto al dominante. Las delimitaciones de la propiedad buscan proteger la libertad de los fundos, no dando lugar a evicción cuando el comprador del bien no ha sido informado sobre ellos y conservando una naturaleza muy heterogénea ${ }^{45}$. Así, éstas configuran el contenido normal del derecho, mientras que las servidumbres vienen a restringirlo y recortarlo ${ }^{46}$. En efecto, pueden diferenciarse las servidumbres de las delimitaciones de la propiedad en que las primeras se constituyen mirando a la utilidad de uno de los predios, mientras que las otras atienden a la necesidad; unas deben establecerse expresamente, mientras las otras se constituyen ipso iure y, por último, las servidumbres perecen por no uso, mientras que las otras no ${ }^{47}$.

El origen de este tratamiento conjunto de las delimitaciones de la propiedad y las servidumbres es bastante curioso. Los romanos no trataron el problema de esta manera. Las limitaciones y delimitaciones de la propiedad tienen una naturaleza muy disímil ${ }^{48}$, tomando, en ocasiones forma de interdictos posesorios, de acciones de fondo, de especificaciones para deslindar los fundos, etc. Por ello el tratamiento de las delimitaciones de la propiedad se encontraba disperso entre diferentes instituciones.

En principio, los bienes inmuebles en Roma debían separarse nítidamente unos de otros a través de una franja de terreno que se consideraba ajena a ambos vecinos. En el caso de los predios urbanos, esta se denominaba ambitus, aunque con el paso del tiempo y según la ciudad de Roma creció y se superpobló este régimen se hizo imposible. En su lugar pasó a considerarse

${ }^{45}$ Ibíd., p. 19.

${ }^{46}$ Así, declara Algarra Prats, Esther, La defensa jurídico-civil frente a bumos, olores, ruidos y otras agresiones a la propiedad y a la persona (Madrid, McGraw-Hill, 1995), p. 16 "Estos límites determinan el contenido normal del derecho de propiedad, a diferencia de las servidumbres que, como limitaciones que son, vienen a recortar desde fuera el contenido del derecho".

${ }^{47}$ Bonfante, Pietro, Corso di Diritto romano. La propietà (Milano, Giuffrè, 1966), II, 1, p. 326.

${ }^{48} \mathrm{Al}$ respecto afirma PARICIO, Javier, La denuncia de obra nueva en el Derecho romano clásico (Barcelona, Bosch, 1982), p. 1: "En el Derecho romano, dada la particular naturaleza del dominium con su carácter absoluto e independiente (salvo que hubiese sido limitado voluntariamente, p.ej. con una servidumbre), las relaciones entre los titulares de los diversos fundos vecinos se nos presenta bajo la forma de un régimen negativo, es decir, de una respectiva libertad tutelada y defendida por diferentes recursos procesales [...]. Lo que existen son medios jurídicos de defensa y no limitaciones a la propiedad; por ello los recursos procesales que se concedían para resolver problemas surgidos en las relaciones de vecindad no pueden ser considerados estrictamente como limitaciones sobre la propiedad". Véase también BIONDI, Biondo, La categoria, cit. (n. 44), p. 20. 
común la pared que dividía a los inmuebles, llamada paries communis ${ }^{49}$ y a establecerse un régimen de obligaciones respecto a la misma. Esta no era considerada como una servidumbre, sino todo lo contrario, había una gran cantidad de actos que no podían realizarse sobre ella sino en cuanto se contase con una servidumbre sobre la misma.

En general, el tema central de las relaciones de vecindad en Roma versaba sobre el poder de exclusión que el propietario de un predio tenía respecto a todas las demás personas, incluidos, por supuesto, sus vecinos ${ }^{50}$. En este sentido, debía protegerse "atmósfera jurídica" de cada predio, por utilizar la expresión de Ihering ${ }^{51}$. Hacer algo en un predio ajeno (facere in alieno) se encuentra, en principio, prohibido. Para ello se requiere la existencia de una servidumbre, que viene a alterar el régimen normal de exclusión de terceros respecto de los bienes propios al imponer la necesidad de padecer algo que realiza el vecino, sea en nuestro propio bien (inmisión directa), sea en el suyo, pero cuyas consecuencias se proyectan en el propio (inmisión indirecta). De ahí que, a propósito de las servidumbres y del derecho que puede asistir al vecino a realizar un acto que se considera inmisivo, se discutió una variedad de casos que parecían dudosos en que debía determinarse si es que existía una servidumbre o no. Para determinar las posiciones jurídicas de las partes y encuadrar el posible juicio sobre aquellos actos que turbaban la posesión de los inmuebles y su inviolabilidad se utilizaban interdictos posesorios, pero una vez establecida la orden de no cambiar la situación fáctica de las fincas debía discutirse el fondo de la cuestión a través de acciones reales ${ }^{52}$. Quien afirmaba que tenía una servidumbre ejercitaba una vindicación de servidumbre, una acción real destinada a reintegrar el ejercicio de dicha servidumbre a su titular. $\mathrm{Si}$, por el contrario, quería negarse la existencia de dicha servidumbre y, por tanto, del derecho a inmitir, se utilizaba una acción real denominada negativa o negatoria, que, al contrario, buscaba defender la libertad del predio ${ }^{53}$.

Aunque en la etapa clásica el tratamiento de las servidumbres era un

${ }^{49}$ Biondi, Biondo, La categoria, cit. (n. 44), p.46.

${ }^{50}$ Ibíd., p. 20.

${ }^{51}$ JHERING, Rudolf von, Jahrbücher für die Dogmatic des heutigen römischen und deutchen Privatrechts (1863), p. 91.

${ }^{52}$ En este esquema de la relación entre acciones de fondo e interdictos posesorios seguimos la tesis de Falcone, Giuseppe, Ricerche sull'origine dell'interdetto "uti possidetis", en Annali del Seminario Giuridico dell'Università di Palermo, 44 (1996), pp. 5-360.

${ }^{53} \mathrm{Al}$ respecto, Gayo (4,3), al tratar las acciones reales presenta esta clasificación: "In rem actio est, cum aut corporalem rem intendimus nostram esse aut ius aliquod nobis conpetere, uelut utendi aut utendi fruendi, eundi, agendi aquamue ducendi uel altius tollendi prospiciendiue, aut cum actio ex diuerso aduersario est negatiua". 
tanto disperso ${ }^{54}$, el Corpus de Justiniano intentó mejorar su sistematización dándoles un tratamiento conjunto ${ }^{55}$ y más ordenado. El problema radica en que este tratamiento tendió a oscurecer dicha categoría dogmática en los siglos venideros.

Justiniano trata de las servidumbres en un libro aparte del Digesto, donde comienza por una parte general acerca de las servidumbres (Dig. 8,1), para continuar por las servidumbres urbanas (Dig. 8,2), luego las rústicas (Dig. 8,3), las reglas comunes a ambas (Dig. 8,4), las acciones relativas a las servidumbres (Dig. 8,5) y, finalmente, la liberación de las mismas (Dig. 8,6). Que la gran división sistemática fuese entre servidumbres urbanas y rústicas tiene sentido en el Derecho romano clásico, toda vez que éstas son res mancipi $\mathrm{y}$, por tanto, sólo pueden constituirse por ceremonias especiales, mientras que aquéllas no. Sin embargo, en el Derecho justinianeo, que elimina dicha categorización, parece algo más oscura la subsistencia de tal división. En cualquier caso, como hemos visto, el problema de las servidumbres radicaba en la facultad de excluir al vecino del inmueble propio, de manera que en el título 8.5, sobre la vindicación y negación de servidumbres se van a discutir también problemas de límites de la propiedad que resultan abordables también desde los interdictos posesorios. Es más, incluso en la discusión de interdictos posesorios en otras partes del Digesto, volverá a aparecer el problema de las servidumbres.

No obstante, Justiniano hizo algo más que esto en su sistematización, puesto que él recoge, específicamente en el Codex, su recopilación de constituciones imperiales, algunos límites de la propiedad bajo el nombre de servidumbres $^{56}$. En la parte occidental del desaparecido Imperio, en cambio, la

${ }^{54}$ Basta con ver la incerteza sistemática respecto a las mismas en la obra de Gayo, donde se las trata entre las cosas incorporales (Gai. 2,14), entre las res mancipi (Gai. 2,17 ) y entre los modos de adquirir (Gai. 2,29). Véase: BIONDI, Biondo, Le servitu (Milano, Giuffrè, 1967), p. 4.

${ }^{55}$ Así, figuran en sus Institutiones 2,3, en el libro VIII del Digesto y en el título $34^{\circ}$ del libro III del Codex.

${ }^{56}$ Ésta tendencia, aparentemente, venía se había extendido en la época Tardía o Postclásica, como una de tantas simplificaciones que experimentó el Derecho en dicha época. Al respecto, aparece en el Codex Theodosianus 4,24 una constitución imperial sobre las distancias que los edificios deben guardar entre sí, no pudiendo ser inferior a diez pies: "De servitute luminis vel aeris similiter constitutum est, ut inter privatorum fabricas decem pedes, inter publicas quindecim dimittantur". Para la parte Oriental del Imperio, el emperador Zenón repite la normativa y promulga nuevamente una constitución imperial en griego que califica este límite legal a las construcciones de servidumbre. Esta está recogida en Cod. Iust. 8,10,12. Justiniano no sólo la recoge sino que incluso la repite y la interpreta, pues, aparentemente habrían existido dudas teóricas en torno a su aplicación. Cod. Iust. 8,10,13 dice: "Imperator Justinianus . Cum dubitabatur, utrum constitutio Zenonis divae memoriae ad Adamantium praefectum urbis scripta, quae de 
simplificación jurídica terminó por hacer desaparecer la categoría dogmática de las servidumbres ${ }^{57}$

Cuando el Corpus iuris de Justiniano fue recibido en Occidente, la institución de las servidumbres experimenta un renacimiento y es a través de este texto que volverán a tener vigencia dentro del panorama jurídico europeo. Parte de la doctrina estima que sería justamente en esta época que la categoría de las servidumbres legales habría sido desarrollada ${ }^{58}$, aunque nosotros no hemos encontrado trazas de ello. En verdad, es cierto que los glosadores y comentaristas mantienen la idea que algunas limitaciones de la propiedad pueden ser concebidas como servidumbres, toda vez que han heredado de Justiniano tal idea, más en su tratamiento y categorización de las servidumbres siguen el esquema del Corpus.

En efecto, la gran sistematización de las servidumbres que regirá durante todo el período comprendido entre la recepción del Corpus iuris y la codificación francesa se encuentra en la obra de Bártolo y se denomina el arbor servitutum $\mathrm{o}$ árbol de las servidumbres ${ }^{59}$. Esta es una suerte de sistematización

servitutibus loquitur, localis est et huic florentissimae urbi dedicata et debent illius quidem iura in hac observari, antiqua vero, quae contraria sunt, locum habere in provinciis: indignum esse nostro tempore putantes aliud ius in hac regia civitate de huiusmodi observari, aliud apud nostros esse provinciales, sancimus eandem constitutionem in omnibus urbibus Romani imperii obtinere et secundum eius definitionem omnia procedere et, si quid ius ex ea lege innovatum est a vetere dispositione, et hoc in provinciis a praesidibus earum observari: ceteris videlicet omnibus, quae non per Zenonianam legem innovata sunt, sed veteribus legibus comprehensa, in sua firmitate in omni loco manentibus. Iust. A. Iohanni PP. D. K. sept. Constantinopoli post consulatum Lampadii et Orestis VV. CC.” [a. 531]. Véanse: BIondi, Biondo, Le serivtù prediali nel Diritto romano (Milano, Giuffrè, 1969), pp. 67-73; El Mismo, La categoria romana delle "servitutes" (Milano, Vita e Pensiero, 1936), p. 23-40; Jiménez Salcedo, María Carmen, El régimen jurídico de las relaciones de vecindad en Derecho romano (Córdoba, Universidad de Córdoba, 1999), p. 25. Para la parte occidental del extinto Imperio, también existe alguna regulación en las leyes dictadas por los reyes bárbaros que asimila a las servidumbres este tipo de prohibiciones. Así lo leemos en la llamada "Lex Romana Burgundionum" (17,6): "De servitute luminis vel aeris similiter constitutum: ut inter privatorum fabricas decem pedes, inter publicas quindecim dimittantur, secundum legem Theudosiani libri iv, sub titulo: de edificiis privatis et publicis".

${ }^{57}$ Esto explica, por ejemplo, su ausencia del Liber Iudiciorum en época visigótica. Véase: Pacheco Caballero, Francisco, Las servidumbres prediales en el Derecho Histórico español (Lleida, Pagés Editors, 1991), p. 125.

${ }^{58}$ Biondi, Biondo, Le serivtú prediali nel Diritto romano (Milano, Giuffrè, 1969), p.75; Bonfante, Pietro, Corso di Diritto romano. La proprietà (Milano, Giuffrè, 1966), II, 1, p. 322.

${ }^{59}$ En principio, la sistemática fue una creación de Bártolo de Sasoferrato; sin embargo fue tan exitosa que en las ediciones posteriores de la Magna Glossa fue incluida como un apartado previo o prefacio al libro VIII del Digesto. Véanse: BARTOLI A 
general de las servidumbres en personales (uso y usufructo), reales (servidumbres propiamente tales) y mixtas a partir de un fragmento interpolado con que se abre el libro de las servidumbres del Digesto ${ }^{60}$. Según esta clasificación, las servidumbres reales se dividirían en urbanas y rústicas, encontrándose la compleja casuística relativa a los actos que no pueden realizarse sin la existencia de una servidumbre comprendida entre las servidumbres rústicas innominadas y algunas servidumbres urbanas. Tal sistematización fue exitosa, al punto que fue adoptada por la generalidad de los tratadistas posteriores. Durante el humanismo jurídico, se mantuvo tal sistemática, con la diferencia que el esquema se puso en un lugar más lógico, no antes del tratamiento de las servidumbres prediales, sino que se adelantó ubicándolo antes de tratar el uso y la habitación y eliminando la categoría de las servidumbres mixtas ${ }^{61}$. En todo caso, es aquí el momento en que comienzan a sentirse algunas diferencias en la dogmática utilizada para el análisis de las servidumbres. En primer término, las definiciones de servidumbre comienzan a seguir nuevos caminos que eventualmente conducirán a la definición del Code, pero también comienza a introducirse variaciones sistemáticas que apartan la institución de la tradición bartolista. Así, hablando de la constitución de las servidumbres nos dice Donellus que estás pueden ser constituidas tanto por la naturaleza como por factores externos ${ }^{62}$, pudiendo ser este hecho externo

Saxoferrato, In primam Digesti Veteris pertem commentaria (Augusta Taurinorum, Nicolau Bevilaquam, 1574, reimpresión de A.J.B. Sirks, Maastricht, 2004), p. 182v; y para la Magna Glossa: Digestum Vetus seu Pandectarum Iuris Civilis (Venetiis, 1592), I, p. 1091.

${ }^{60}$ Dig. 8,1,1: "Marcianus libro tertio regularum. Servitutes aut personarum sunt, ut usus et usus fructus, aut rerum, ut servitutes rusticorum praediorum et urbanorum" ("Las servidumbres son personales, como el uso y el usufructo, o reales, como las servidumbres sobre los predios rústicos y urbanos"). El fragmento original proviene del jurista Marciano, de su libro acerca de las reglas, un texto probablemente de carácter pedagógico que posiblemente intentase reducir a categorías generales los derechos en cosas ajenas. A nosotros nos parece probable que el originalmente el fragmento dijese iura praediorum aut personarum [...]. Sin embargo puede que el jurista haya efectivamente creado una supercategoría de servidumbres que englobase a todos los derechos en cosas ajenas, aunque esta forma mental, propia de un pedagogo, no haya prosperado. En cualquier caso, aunque el fragmento fue incluido en un lugar predominante del libro de las servidumbres del Digesto, es manifiesto que esta categoría no se utiliza para nada más, puesto que el uso y el usufructo están tratados en otro lugar y no a propósito de las servidumbres.

${ }^{61} \mathrm{Al}$ respecto, Donelli, Hugonis, Opera Omnia. Comentariorum de iure civili (Maceratae, Osualdi Hilligeri, 1839), III, pp. 3-4, sigue esta línea y pasa de las servidumbres en general a las urbanas, las rústicas y las reglas relativas a las acciones confesoria y negatoria.

${ }^{62}$ Ibíd., III, p. 295: "De acquirenda praedii servitute. Acquiri tunc, cum recte constituta est. Constitui Natura aut Externo facto”. 
tanto nuestro (convenciones y pactos) como ajeno, que vendrían a ser los actos de los jueces. No tenemos aquí la teoría de las servidumbres naturales, legales y convencionales, pero sí algunas de sus notas.

Sin embargo, los juristas del racionalismo parecen volver a los esquemas bartolistas. En efecto, Domat mantiene una sistemática tradicional, distinguiendo entre servidumbres personales y reales, y centrando su tratamiento en la diferenciación entre rústicas y urbanas. Como siempre, algunas delimitaciones de la propiedad quedan tratadas entre las servidumbres, como consecuencia del orden sistemático del Digesto de Justiniano que Domat sigue al pie de la letra ${ }^{63}$. Pothier, por su parte, también representa una continuidad con el pasado respecto a su tratamiento de las servidumbres. En efecto, él sigue la división tradicional entre servidumbres reales y personales $\mathrm{y}$, a continuación, trata las urbanas y rústicas para concluir de la misma manera que el Corpus ${ }^{64}$, con la salvedad que aquéllas relaciones de vecindad y delimitaciones del dominio, que tradicionalmente eran tratadas como servidumbres, son concebidas por él como cuasi contratos y, por lo tanto, separadas y tratadas aparte.

El gran cambio sistemático respecto al tratamiento tradicional de las servidumbres se produce con el Code Napoléon. Este no sólo contempla una definición de servidumbres extravagante, en pasivo y producto de la recepción de ideas bizantinas en la Francia del siglo XVI, sino que introduce una categorización del todo exótica en la institución, incluyendo formalmente una variada casuística relativa a los límites de la propiedad y a los interdictos posesorios dentro de las servidumbres. Falcone apunta que la definición provendría de una obra del siglo XVI que tuvo la fortuna de ser recogida en una recopilación del siglo XVIII por Meerman ${ }^{65}$. Sin embargo, el jurista en cuestión sólo tiene por particularidad el adoptar la definición de Teófilo para las servidumbres reales y, por tanto, realizar un variación en un tema conocido, toda vez que su tratamiento de las servidumbres sigue el modelo y tradicional en lo demás, sin hacer referencia a la clasificación de las servidumbres en naturales, legales y convencionales. Por otro lado, dicha obra, escrita en latín y editada en Holanda, difícilmente pudo tener un nivel de difusión suficiente en la Francia napoleónica como para imponerse sobre el mismo Pothier prácticamente sin discusión alguna en la comisión

${ }^{63}$ Domat, Jean, Oeuvres complètes (Paris, Alex-Gobelet, 1835), IV p. 188.

${ }^{64}$ Pothier, R.-J., Cotume d'Orléans, en OEuvres (Paris, Videcoq, 1845), I pp. 312 318.

${ }^{65}$ La obra sería MeErman, Gerard, Novus thesaurus iuris civilis et canonici (Rotterdam, Petrus de Hond, 1751). Cfr. Falcone, Giuseppe, Note historique sur la définition législative de la servitude (article 637 Code Napoléon - article 1027 Cod. Civ. It.), en Revue Historique de Droit Français et Étranger, 79 (2001) 1, pp. 13-30. 
codificadora $^{66}$. Parece que la comisión ya había asumido esta categorización dogmática y que, por tanto, es a otra obra a la que le corresponde el dudoso honor de haber inspirado a la comisión en este punto. En efecto, pocos años antes del proyecto Cambacérès se publicó una obra de carácter monumental y estilo forense, muy propia del gusto de la ilustración. Se trata de una suerte de enciclopedia jurídica llamada Répertoire universal et raisonné de jurisprudence, que adquirió gran popularidad en su tiempo. En ella, en su tomo 58 encontramos un tratamiento sistemático de las servidumbres que sirve de antecedente a la codificación francesa. En efecto, ahí se recoge no sólo una definición de servidumbre como carga, es decir, en pasivo ${ }^{67}$, sino que también se adopta el modelo de Donellus de fuentes de las servidumbres, pero se lo transforma en el eje sistemático de las mismas, variando, eso sí, su clasificación en servidumbres naturales, legales y convencionales ${ }^{68}$. Las relaciones de vecindad pretenden normarse a través de las servidumbres legales ${ }^{69}$ y se comprenden entre ellas cuestiones que tradicionalmente no habían recibido dicho tratamiento, como la medianería y el cercamiento. En pocas palabras, esta obra constituiría la base dogmática del Code Napoléon en su tratamiento de las servidumbres. Su difusión y prestigio en el medio forense explicaría la rápida adopción de su sistemática por la comisión codificadora, la cual, por lo demás, deseaba apartarse del derecho feudal que había antecedido a la codificación ${ }^{70}$. En un ánimo revolucionario se adoptó una nomenclatura confusa y una sistemática deficiente que terminó, en el caso francés, por relegar las relaciones de vecindad fuera de las servidumbres y obligó a crear, para su regulación, un complejo sistema de responsabilidad que hace acrobacias intelectuales para encuadrar este tema dentro de la responsabilidad extracontractual.

${ }^{66}$ En efecto, cuando se consultan las actas de la misma llama mucho la atención la manera acrítica en que se abraza una forma tan revolucionaria de concebir las servidumbres. El título entero de las servidumbres es adoptado de manera unánime con algunas observaciones menores. Véase: FENET, P.A., Recueil complet des travaux préparatoires du Code Civil (Paris, 1827), XI, pp. 281-291.

${ }^{67}$ Guyot, Répertoire universel et raisonné de jurisprudence civil, criminelle, canonique et bénéficiale (Paris, Panckoucke, 1783), CVIII, p. 232 "L'assujettissement d'un domaine à un autre domaine, au à une personne, en vertu duquel le possesseur est obligé d'y souffir certaines charges ou incommodités, au profit d'autrui, comme l'écoulement des eaux de la maison voisine, un passage, une vue, etc.".

${ }^{68}$ Ibíd., p. 238.

${ }^{69}$ Ibíd., p. 240.

${ }^{70}$ Así, por ejemplo, PARdesus, J. M., Traité des servitudes ou services fonciers (Paris, Thorel, 1838), I, p.4-5, afirma que incluso debería cambiarse el nombre a la institución para que no se la confundiera con aquella que habría regido durante el antiguo régimen. Este libro es el tratado más popular acerca de servidumbres después de la codificación. 
El problema principal es que "las obligaciones de vecindad no son servidumbres, sino que las servidumbres surgen cuando las mismas relaciones de vecindad son modificadas, es decir, el acuerdo destruye la regla común y surge la servidumbre" ${ }^{\text {"11 }}$. De hecho, al poco andar resultó evidente que muchas de las cosas que habían recibido tal denominación no respondían a la categoría dogmática de servidumbres ${ }^{72}$. Algunas sí que pueden concebirse como tales, en la medida que efectivamente afirmen un derecho que pesa sobre el predio ajeno y puedan deslindarse efectivamente las posiciones de predio sirviente y dominante, mientras que en otras tal categorización parece imposible e, incluso, se conservan normas de carácter heterogéneo que resulta difícil encuadrar dentro de cualquier institución.

Uno de los casos más notorios se encuentra en el artículo 856 del Código Civil, tomado del 674 del Code, donde se encuadra dentro de las servidumbres legales una suerte de deber general de no inmitir en el fundo vecino, es decir, una servidumbre legal iun probibiendo de no inmitir en lo ajeno ${ }^{73}$. Esta norma, por la particular historia del Código Civil que recoge los casos de relaciones de vecindad entre las servidumbres legales, para luego volver a tratarlos entre los interdictos posesorios, se encuentra repetida en el artículo 941 del Código:

Mientras el artículo 856: "Si se trata de pozos, letrinas, caballerizas, chimeneas, hogares, fraguas, hornos u otras obras de que pueda resultar daño a los edificios o heredades vecinas, deberán observarse las reglas prescritas por las ordenanzas generales o locales, ora sea medianera o no la pared divisoria. Lo mismo se aplica a los depósitos de pólvora, de materias húmedas o infectas, y de todo lo que pueda dañar a la solidez, seguridad y salubridad de los edificios"; el artículo 941 inciso $1^{\circ}$ señala: "El dueño de una casa tiene derecho para impedir que cerca de sus paredes haya depósitos o corrientes de agua, o materias húmedas que puedan dañarla".

Ambos casos derivan de la casuística romana, específicamente de Dig. $8,5,17,2^{74}$, donde se consulta al jurista Alfeno sobre un estercolero que se

${ }^{71}$ García SÁnchez, Justo, Teoría, cit. (n. 1), p. 16.

${ }^{72}$ Así, por ejemplo, Claro Solar, Luis, Explicaciones de derecho civily comparado. De los bienes (Santiago, Nascimento, 1935), IX, 4, p. 21, afirma: "Si el legislador ha admitido estas numerosas limitaciones del derecho de propiedad a que se da el nombre de servidumbres, se debe a que ellas procuran una ventaja apreciable a otro predio, que mediante ellas puede ser mejor utilizado y explotado".

${ }^{73}$ Biondi, Biondo, La categoria romana delle "servitutes" (Milano, Vita e Pensiero, 1936), pp. 335-337.

${ }^{74}$ Dig. 8,5,17,2 (Alfenus, 2 digestorum): "Secundum cuius parietem vicinus sterculinum fecerat, ex quo paries madescebat, consulebatur, quemadmodum posset vicinum cogere, ut sterculinum tolleret. Respondi, si in loco publico id fecisset, per interdictum cogi posse, sed si in privato, de servitute agere oportere: si damni infecti stipulatus esset, possit 
ubica junto a una pared en el linde de una finca. La respuesta que aparece en el Digesto $^{75}$ como proveniente del jurista es bastante interesante. Dice que puede haber lugar tanto a un interdicto como a una acción de servidumbres. Dentro de la tradición francesa, que encuadraba las relaciones de vecindad como un problema de servidumbres legales, naturalmente que el problema fue enfocado desde esa perspectiva y recibido en el artículo $674 \mathrm{del} \operatorname{Code}^{76}$. Sin embargo, puesto que la legislación Napoleónica había decidido dejar los problemas de vecindad a los reglamentos administrativos, se hizo una expresa referencia a los reglamentos y usos. Este mismo artículo fue tomado por las codificaciones española ${ }^{77}$ e italiana de $1865^{78}$, aunque con resultados muy diversos al caso francés, pues en dichos ordenamientos se construyó la teoría de las inmisiones en base a este precepto ${ }^{79}$.

per eam stipulationem, si quid ex ea re sibi damni datum esset, servare" (Fui consultado acerca de un vecino que había hecho un estercolero en la pared, por el cual la deterioraba y de cómo litigar y hacerlo retirar el estercolero. Respondí que si afectaba a un lugar público, podía ser cogido por un interdicto, si a un lugar privado, se puede litigar por la [inexistencia] de la servidumbre. Si se estipuló caución de daños, puede litigarse por la estipulación para que repare los daños causados).

${ }^{75}$ En todo caso, el fragmento es sospechoso de interpolaciones. No trataremos ese problema pues parece específico del Derecho romano y, por lo demás, la influencia del mismo se dio no desde el original clásico, sino desde la versión justinianea que aparece en el Digesto. Sin embargo, para conocer la controversia en detalle véase: GARCía SÁNCHEz, Justo, Teoria, cit. (n. 1), pp. 61-69. Para el desarrollo de la tradición medieval de glosadores y comentaristas al respecto, véase: LÁZaro Guillamón, Carmen, $L a$ acción negatoria (Valencia, 2007, Tirant lo Blanch), pp. 112-113.

76 "Celui qui fait creuser un puits ou une fosse d'aisance près d'un mur mitoyen ou non, celui qui veut y construire cheminée ou âtre, forge, four ou fourneau, y adosser une étable, ou établir contre ce mur un magasin de sel ou amas de matières corrosives, est obligé à laisser la distance prescrite par les règlements et usages particuliers sur ces objets, ou à faire les ouvrages prescrits par les mêmes règlements et usages, pour éviter de nuire au voisin”.

${ }^{77}$ El Artículo 590 del Código Civil Español señala: "Nadie podrá construir cerca de una pared medianera pozos, cloacas, acueductos, hornos, fraguas, chimeneas, establos, depósitos de materias corrosivas, artefactos que se muevan por vapor, o fábricas que por si mismas o por sus productos sean peligrosas o nocivas, sin guardar las distancias prescritas por los reglamentos y usos del lugar, y sin ejecutar las obras de resguardo necesarias, con sujeción, en el modo, a las condiciones que los mismos reglamentos prescriban".

${ }^{78}$ Artículo 574 Codice Civile de 1865: "Chi vuole fabbricare contro un muro comune o divisorio, ancorchè propio, camini, forni, fucine, stalle, magazzini di sale o di materie atte a danneggiarlo, ovvero stabilire in vicinanza della proprietà altrui macchine messe in moto dal vapore, od altri manufatti, per cui siavi pericolo d'incendio, o di scoppio, o di esalazioni nocive, deve eseguire le opere e mantenere le distanze, che secondo i casi siano stabilite dai regolamenti, e in loro mancanza, dall'autorità giudiziaria, affine di evitare ogni danno al vicino".

${ }^{79} \mathrm{Al}$ respecto, véanse: EgEA FernándeZ, Joan, Acción negatoria, inmisiones y defensa de la propiedad (Madrid, Marcial Pons, 1994), p. 71; Algarra Prats, Esther, 
En cuanto al artículo 941, éste toma el mismo caso, pero mirando el problema desde la perspectiva de las acciones posesorias. Al respecto sigue la tradición de las Partidas, donde el problema se trataba en dicha sede, y específicamente de la ya citada part. III, tìt. $32^{\circ}$, ley $13^{\text {a }}$. Bello toma de aquí su tratamiento dentro de las querellas posesorias y reitera el caso.

Respecto al artículo 856, Alessandri ${ }^{80}$ critica la disposición sin comprenderla, creyéndola impropia de un Código Civily más adecuada para una ley de municipalidades, lo cual es cierto en el caso de Francia, donde la intención del Code era que las relaciones entre vecinos se regulasen por los reglamentos de policía. Sin embargo, en nuestro Derecho, el alcance de la disposición es mayor, toda vez que contempla una limitación del uso de los bienes propios en perjuicio del vecino, lo que tendrá consecuencias dogmáticas interesantes. Claro Solar, que lo entendió de esta manera ${ }^{81}$, estimaba que ambos artículos, el 856 y el 941 son complementarios, aplicándose el artículo 941 cuando había resultado conculcada la norma del $856^{82}$. Esta idea tiene, sin embargo, el defecto de no considerar que a todo remedio posesorio debe corresponderse también una acción de fondo, de manera que si la acción del 941 está dirigida a resguardar el derecho establecido en el 856, ¿cuál sería la acción de fondo que tiene esta misma función, no ya en sede cautelar, sino sustantiva? En pocas palabras, así como una querella de restitución tiene una correspondencia en la acción reivindicatoria, ¿cuál sería la acción de fondo que se corresponde con la querella posesoria especial del 941? Nosotros postulamos que se trata de la acción negatoria.

En principio, y siguiendo a Claro Solar, podemos decir que ${ }^{83}$ "el artículo 856, colocado en el título de las servidumbres, no importa otra cosa que una restricción de los propietarios para disponer de su predio a su antojo [...]. Esta disposición restringe el derecho de los dos propietarios vecinos, a fin de evitar que recíprocamente puedan dañarse en su derecho de dominio [...]. Pero, si a pesar de observarse las prescripciones de las ordenanzas el

La defensa jurídico-civil frente a humos, olores, ruidos y otras agresiones a la propiedad y a la persona (Madrid, McGraw-Hill, 1995), p. 81; Del Arco Torres, Miguel Ángel Pons GonzÁlez, Manuel, Régimen jurídico de las servidumbres (Granada, Comares, 2002), p. 639; DíAz Romero, María del Rosario, La acción negatoria frente a inmisiones en el derecho de propiedad, en Estudios jurídicos en homenaje al profesor Luis DiezPicazo (Madrid, Thomson, 2003), III, p. 3700; y Lázaro Guillamón, Carmen, La acción negatoria (Valencia, Tirant lo Blanch, 2007), p. 168.

${ }^{80}$ Alessandri Rodríguez, A., De los bienes, cit. (n. 4), p. 309.

${ }^{81}$ Claro Solar, Luis, Explicaciones de Derecho civil chileno y comparado. De los Bienes (Santiago, Imprenta Cervantes, 1930), IV, 1, p. 162.

${ }^{82}$ Ibíd., p.364.

${ }^{83}$ Ibíd., p. 348. 
daño se produjere, el propietario de a casa podría reclamar a fin de impedir sus consecuencias". En el mismo se enuncia una serie de actividades que el dueño de un predio puede realizar en su propio bien, de las cuales se proyectan consecuencias negativas en los predios vecinos. La enumeración es, por supuesto, netamente ejemplar, como revela la coletilla "u otras obras" que se agrega a continuación. Todas las actividades tienen por común denominador la emisión de sustancias fuera del espacio jurídico del inmueble donde se producen, como es el caso de las chimeneas, de las fraguas y de los hornos, resultando los predios vecinos perjudicados por tales actividades. La norma, a pesar de estar comprendida dentro de la medianería, no se limita a los perjuicios que se causen en dicha pared, toda vez que expresamente señala que lo mismo da dicha cualidad. El sentido de la norma, al igual que el caso romano de donde está tomada, es más amplio y abarca cualquier tipo de acto que proyecte perjuicios al predio vecino, aunque éste se realice en el inmueble propio. En principio, el artículo remite a las ordenanzas generales o locales para establecer el límite que deberá soportar el vecino respecto a dichas inmisiones. Independientemente del hecho de existir recursos administrativos para el caso de no observarse tales límites, parece evidente que el vecino que resulta perjudicado por dichas actividades deberá tener una acción de fondo que le permita dirigirse directamente en contra del emisor, sin necesidad de confiar en la mayor o menor diligencia de la administración para fiscalizar el cumplimiento de su normativa. Es cierto que a través del artículo 941 podría actuar con una acción posesoria, pero debe plantearse el caso de qué sucede si no puede recurrir por tal vía, si los plazos se encuentran prescritos y se requiere de una acción de fondo. Lo que se reclama es la libertad del fundo, el hecho de no estar sujeto a soportar una inmisión por no existir servidumbre alguna que haya alterado la situación de inviolabilidad de los predios. En principio, para reclamar el ejercicio pleno de los atributos del dominio corresponde el ejercicio de acciones reales, pero el Código Civil solamente reglamentó el ejercicio de la acción reivindicatoria, la cual puede utilizarse para reclamar los demás derechos reales cuando no se está en posesión de ellos (artículo 891). Sin embargo, en el caso lo que se pretende no es exigir la posesión de un derecho real, sino todo lo contrario, negar la existencia de una servidumbre que ponga al vecino en la necesidad de soportar la inmisión. En derecho romano ${ }^{84}$ y comparado ${ }^{85}$ se conoce a esta

${ }^{84}$ Gai. 4,3.

${ }^{85}$ Podemos señalar que hoy por hoy se encuentra recogida legislativa o jurisprudencialmente en la mayor parte de los códigos europeos. A modo ejemplar señalamos que está contenida en el parágrafo 906 del BGB, el artículo 684 del Código Civil suizo, el artículo 364 del Código Civil austriaco, el artículo 844 del Código Civil italiano de 1942, el 1346 del Código Civil portugués, el artículo 1003 del Código Civil griego. 
acción como negatoria. Puesto que por el principio de inexcusabilidad, los tribunales de justicia no podrían dejar de pronunciarse respecto a una acción que intente hacer valer el imperio del artículo $856 \mathrm{del}$ Código Civil, aunque no se hubiese establecido una reglamentación propia para ella, bastaría con interponer una acción meramente declarativa que intente establecer que las inmisiones sufridas por el predio no han de ser soportadas, salvo que existiese una servidumbre, y que se declare que en el caso particular ésta no existe. Esta sería la acción negatoria, cuya ausencia la doctrina ya ha reclamado ${ }^{86}$ y que hemos desarrollado con mayor detalle en otro lugar ${ }^{87}$. De momento, baste con saber que el artículo 856 contempla un principio general de uso limitado de la propiedad, toda vez que prohíbe la realización de actos cuyo resultado sea de carácter inmisivo en la propiedad vecina, concordante con el sentido de la coletilla final del artículo 582, y que, en principio, puede hacerse valer a través de una acción de fondo que denominamos negatoria.

\section{ACCIONES POSESORIAS Y RELACIONES DE VECINDAD}

Llegados a este punto, nos corresponde ahora intentar un somero análisis del tratamiento que da el Código Civil a las relaciones de vecindad en el ámbito de las acciones posesorias, puesto que, producto de la secular tradición hispánica, pero de una manera bastante innovadora, abordó las consecuencias de las inmisiones entre vecinos desde el punto de vista no sólo del dominio y las servidumbres, sino también dentro de la óptica de las acciones posesorias.

En dicha materia el sistema de fuentes del Código Civil se simplifica

${ }^{86}$ Así, Claro Solar, Luis, Explicaciones de Derecho civily comparado. De los bienes (Santiago, Nascimento, 1935), IX, 4, p. 384, señala: "Nuestro Código ha mantenido los principios del antiguo derecho español de las Partidas y del Derecho romano; y en la estructura y método adoptado en este título, ha seguido a Pothier... La acción que nace del derecho de usufructo, del derecho de uso o de habitación y de las servidumbres, y que persigue el reconocimiento de uno de estos derechos, se llama confesoria, confessoria, en oposición a la acción negatoria del propietario de la cosa que sostiene que la cosa no está gravada, pero en sí mismas, en todas ellas, se persigue la vindicación del derecho, su reconocimiento, y se designan en el Código con una denominación común”. Recientemente la crítica ha sido más insistente en poner de relieve el vacío legal existente en nuestras acciones reales y, también, en proponer soluciones al respecto. Véanse: Míguez NúÑEZ, La acción negatoria, en Revista de Derecho de la Universidad Católica de la Santísima Concepción, 12 (2004), pp. 129-135; y LATHorp GómEz, Fabiola, Procedencia de la acción meramente declarativa del dominio en el Derecho chileno, en Ius et Praxis, 17 (2011) 2, pp. 3-24

${ }^{87}$ Véase: Amunátegui Perelló, Carlos, "No siendo contra derecho ajeno": hacia la formulación de una teoría de las inmisiones en nuestro Código Civil, en Revista Chilena de Derecho, 36 (2009) 3, pp. 505-525. 
notablemente, toda vez que Bello no bebió del Code Napoléon en su tratamiento de las acciones posesorias, como tampoco de la tradición francesa. De hecho, tanto el Code francés, como la mayor parte de los códigos de la primera parte del siglo XIX no trataron de las acciones posesorias, sino que dejaron esta materia a los códigos adjetivos de procedimiento civil, donde se las trata. Sin embargo, Bello, siguiendo la tradición hispana, decidió incluirlos a continuación de las servidumbres, al modo de las Partidas. En su época, lo normal era incluirlos en la sección relativa a los procedimientos y acciones ${ }^{88}$, tratarlos conjuntamente con la posesión ${ }^{89}$ o a propósito de la prescripción ${ }^{90}$, pero Bello tomó conscientemente un camino distinto en este punto. Sin embargo, su tratamiento al respecto es bastante más que una mera recepción del derecho vigente, toda vez que en su proyecto original de 1853 había intentado retrotraer la institución al más puro Derecho romano reintroduciendo, luego de haber desaparecido desde hacía siglos, el interdicto utrubi para permitir conservar la posesión de las cosas muebles ${ }^{91}$. Aunque, en definitiva, tal idea no prosperó y la Comisión Revisora no adoptó la propuesta original de Bello, la redacción definitiva de la mayor parte de los artículos relativos a las acciones posesorias sigue, en todo caso, al "Proyecto de 1853".

$\mathrm{Al}$ respecto, Bello establece varios tipos diversos de acciones posesorias. En el título $13^{\circ}$ construye dos acciones de carácter general, por una parte, la acción de amparo para conservar la posesión, y por otra la acción de restitución para la recuperar la posesión perdida. Éstas provienen fundamentalmente de la visión que Bello tenía de los interdictos posesorios romanos uti possidetis, para conservar la posesión, y unde vi, para recuperarla. En efecto, si se compara el artículo 921, donde se establece el objeto de estos interdictos, con sus Instituciones de Derecho romano, esto parece bastante evidente ${ }^{92}$. A

${ }^{88}$ Las Institutiones de Gayo, y por consecuencia, las de Justiniano, tratan de los interdictos posesorios en el libro IV, relativo a las acciones. Este es el orden tradicional para estudiar la materia, y el seguido, por ejemplo, por Sala, que sirvió de base a don Andrés Bello, como veremos más adelante. Véase: SALA, Juan, Ilustración del Derecho Real de España (Madrid, Imprenta Real, 1832), lib. III, tít. 11º, parágrafos 10 ss.

${ }^{89}$ Aquí la suele tratar la tradición francesa siguiendo a Pothier. Así, por ejemplo: Pothier, R.-J., Traité de la possession, en Oeuvres (Paris, Delamotte, 1846), IX, pp. 292314.

${ }^{90}$ Por ejemplo, Troplong, Raymond Théodore, Le droit civil expliqué. De la prescription (Paris, Charles Hingray, 1835), I, 459 ss.

${ }^{91}$ En efecto, el artículo 1069 del "Proyecto de 1853", equivalente al actual 916, disponía: "Las acciones posesorias tienen por objeto conservar o recuperar la posesión". En cambio, en el llamado "Proyecto Inédito", la redacción había cambiado hacia su forma actual en el artículo 1069: "Las acciones posesorias tienen por objeto conservar o recuperar la posesión de bienes raices y de los derechos reales constituidos en ellos".

${ }^{92}$ En el "Proyecto de 1853" el artículo 1073 era el artículo 921 actual, que establece: 
continuación, en el título XIV trata de las acciones posesorias especiales, donde recoge la rica casuística de las Partidas estableciendo acciones posesorias especiales para algunos casos concretos de prácticas turbatorias. En este sentido, las acciones del título $13^{\circ}$ son de carácter general, puesto que resultan aplicables ante cualquier tipo de conflicto posesorio, mientras que las del título $14^{\circ}$ son especiales, toda vez que regulan ciertos conflictos que resultan más frecuentes generalmente entre vecinos, aunque no en todos los casos.

Respecto al modelo seguido en el articulado de las acciones posesorias, Amunátegui Reyes, en el llamado "Proyecto Inédito"93, identificó una nota manuscrita que remitía a dos obras, a saber: "Sala, Derecho real, Libro III, título 11, número 11 y Gómez, Tauri, Ad legem 45, n 194”. El primero de ellos, se refiere a la obra de Juan Sala, Ilustración del Derecho Español ${ }^{94}$, tratado de gran prestigio en la época, que por su método axiomático sirvió de inspiración directa para el articulado de las acciones posesorias. La segunda es la obra de Antonio Gómez, Ad leges tauri commentarium, que se encuentra citada por Sala a propósito del problema. En efecto, cuando se compara el lenguaje utilizado por Sala con aquél empleado al punto por Bello parece del todo evidente que se está siguiendo dicha obra y será ésta la que nos dé algunas claves para comprender las acciones posesorias. Nosotros pretendemos en este acápite simplemente mostrar como estas acciones recogen la casuística relativa a las relaciones de vecindad y de qué forma la protección de la posesión y la prohibición de las inmisiones se encuentran íntimamente relacionadas en el Código Civil. Es por ello que dejaremos de lado la acción de restitución, que no nos interesa para nuestros fines, para centrarnos en las demás acciones posesorias contempladas. La visión aquí presentada será de carácter general, pues en otro lugar expusimos con cierto detalle la aplicación misma de las querellas posesorias.

Con cierta perplejidad declara Alessandri que sólo dos de las accio-

"Elposeedor tiene derecho para pedir que no se le turbe o embarace su posesión o se le despoje de ella, que se le indemnice del daño que ha recibido, y que se le déseguridad contra el que fundadamente teme". Compáreselo con lo dispuesto por Bello, en sus Instituciones de Derecho romano: "Son interdictos retinendae, el uti possidetis y el utrubi. Dase el primero al poseedor de una finca que al tiempo de la listiscontestación la posee nec vi, nec clam, nec precario, contra el que turba esta posesión, para que desista, le indemnice y le preste fianza de non turbando".

${ }^{93}$ El llamado "Proyecto Inédito" se ve en: Bello, Andrés, Proyecto de Código Civil, en Obras completas (Santiago, Nascimento, 1932), V, pp. 264-265.

${ }^{94} \mathrm{Al}$ respecto, véase: Barrientos Grandón, Javier, Juan Sala Bañuls (17311806) y el Código Civil de Chile (1855), en Revista de Estudios Histórico-Jurídicos, 31 (2010), pp. 351-368. 
nes tratadas por Bello son posesorias ${ }^{95}$, cuestión que revela, más bien, su comprensión estrecha de la conservación de la posesión y del objeto de las acciones posesorias en general. Parece sorprenderle que no todas ellas estén destinadas a prevenir el despojo posesorio. Esta perplejidad revela más bien la pobre comprensión que el autor tiene de la protección posesoria, antes que constituir una verdadera limitación del Código Civil. En efecto, la posesión consiste básicamente en la detentación material de la cosa, la cual se traduce en el ejercicio de actos posesorios en ella, es decir de actividades donde de hecho se ejerzan las facultades del dominio, sean de uso, goce o disposición. Turbar la posesión no es sólo despojar al detentador del bien, sino también impedirle de hecho el ejercicio de dichos actos posesorios. De ahí que la casuística romana incorporara a las acciones posesorias como una herramienta para detener las conductas de carácter inmisivo que el vecino realizase en sus propios bienes, pero cuyas consecuencias se manifestasen en los bienes ajenos. Especialmente notable es el caso de la taberna de quesos (Dig. 8,5,8,5), donde amén de entregarse la acción de fondo contra quien emitía los humos, el jurista expresa que cabe el interdicto posesorio uti possidetis para reprimir tal conducta ${ }^{96}$, es decir, el antecedente directo de nuestra querella de amparo ${ }^{97}$.

${ }^{95}$ Alessandri Rodríguez, A., De los bienes, cit. (n. 4), p. 221; reiterado en VoDANovic, Antonio, Derecho civil basado en las explicaciones de los profesores de la Universidad de Chile Arturo Alessandri Rodriguez y Manuel Somarriva Undurraga. De los sujetos y los objetos del Derecho (Santiago, Nascimento, 1940), II, p. 664.

${ }^{96}$ Concordamos con Jiménez SaLCEDo, María Carmen, El régimen jurídico de las relaciones de vecindad en Derecho romano (Córdoba, Universidad de Córdoba, 1999), p.54, cuando afirma: "no es de extrañar que la prohibición de immittere in alienum se erigiera en la norma fundamental reguladora de las relaciones de vecindad. Las inmisiones en inmueble ajeno son en principio ilícitas. De manera que el perjudicado por una immissio está legitimado para impedirla y en caso de persistencia de la misma, tiene a su disposición los interdictos uti possidetis y quod vi aut clam, e incluso si quien perturba pretende tener derecho a ello, las acciones negatorias correspondientes". No obstante, existe un problema relativo a la autenticidad de aquella parte del fragmento que declara aplicable el interdicto uti possidetis. Al respecto, De Martino, Francesco, $D$. 8.5.8.5: i rapporti di vicinato e la tipicità delle servitú, en Diritto, Economia e società nel mondo romano (Jovene, Napoli, 1995), I p. 524, piensa que corresponde a un glosema insertado al final de la respuesta del prudente, manteniendo en lo demás la sustancial autenticidad del fragmento. No obstante, en un artículo bastante breve CAPOGROssi Colognesi, Luigi, Actor and Defendant in Negatoria Servitus, en CAIrns, John W. - Robinson, Olivia F. (editores), Critical Studies in Ancient Law, Comparative Law and Legal History (Oxford and Portland, Oregon, 2001), pp. 31-36, ha establecido la íntima conexión que existe en materia de servidumbres entre la posición que ocupará en vindicante y el que niega la servidumbre y el ejercicio de interdictos posesorios, cuya función primordial parece haber sido justamente esta. De ahí que nosotros nos inclinamos por la autenticidad de la referencia, aunque tal vez se encuentre algo resumida.

${ }^{97}$ No sólo es en el caso de la taberna de quesos de Dig. 8,5,8,5 en que se entrega la 
$\mathrm{Al}$ respecto, durante el Medioevo se mantuvo la idea de la finalidad protectora de los interdictos posesorios en materias de vecindad cuando no se intenta disputar la posesión del bien, sino que simplemente se realizan sobre él inmisiones que turban o molestan en el ejercicio de actos posesorios ${ }^{98}$. Esta idea también es recibida por las Partidas, antecedente inmediato de nuestro sistema de acciones posesorias.

Si el Código Civil exige la prueba para de la posesión en materia de acciones posesorias el acreditar que se han efectivamente ejercido hechos positivos de uso y goce (artículo 925), es porque el objetivo de las acciones posesorias no es simplemente defender del despojo, sino también de los impedimentos fácticos al ejercicio material de las facultades del dominio. En efecto, la contraposición entre turbaciones por inmisión y servidumbres, latente en la casuística romana, se expresa en el artículo 947, que declara inadmisibles

solución interdictal al problema de las inmisiones de humos, también en problemas de aguas: D. 39,3,11; 43,8,2,28; 39,3,3 pr.; 39,3,1,17; 39,3,2,10; o de cloacas: Dig. $43,23,1,9 ; 43,23,1,15$; y muchos otros.

${ }^{98} \mathrm{Al}$ respecto, podemos citar una tradición ininterrumpida de textos en tal sentido. Así, sobre este caso expresa Accursius, In Digestum Vetus (Venetiis, 1552), pars prima, p. 1179 nota a: "Hic ergo datur pro quasi possessione servitutis, vel libertatis. Vel dic quod vera possessione rei quae inquietatur pro servitute quam non debet. Et econtra pro vera possessione rei dominantis, que inquietatur, eo quod servitute debita uti non permittitur" "“Aquí, por tanto, se da [el interdicto posesorio] en favor de la cuasi posesión [de la servidumbre] o por la libertad [del fundo]. Se dice que la verdadera posesión de la cosa se inquieta por una servidumbre [de humos] que no se debe. Y en contra de la verdadera posesión del bien dominante, cuando se inquieta por no permitirse el ejercicio de de la servidumbre debida").

${ }^{\text {Por }}$ su parte, BARTOLI A SAXOFERRATO, In primam digesti Veteris pertem commentaria (Augusta Taurinorum, Nicolau Bevilaquam, 1574, reimpresión de A.J.B. Sirks, Maastricht, 2004), p. $380=190 \mathrm{v}$, señala: "Dominus partis inferiores non potest in superiores iure servitutis fumum immittere et dominus partem superioris non potest in inferiores immittere aquam, nisi aliud actum fit, et p his competunt hae actiones et interdicta possessoria" ("El dueño de la parte inferior no puede en los [pisos] superiores inmitir humo salvo que tenga el derecho de la servidumbre. Por su parte, tampoco puede el dueño de los pisos superiores inmitir agua en los [pisos] inferiores, ni hacer ningún otro acto. Y por ello competen estas acciones e interdictos posesorios"). BALDI UBALDI PeRUSINI, In primam Digesti Veteris partem commentaria (Venetiis, 1577, reimpresión de A.J.B. Sirks, Maastricht, 2005), p. 325 = 330, mantiene la misma línea, aunque es más sintético: "Non licet in alienum immittere, et pro incorporalibus sunt prodita iudicia possessoria" ("No se permite inmitir en lo ajeno y por los [derechos] incorporales [en este caso de servidumbre] se otorgan juicios posesorios"). Por último, Pablo de Castro, In Digestum (Venetiis 1582, reimpresión de A.J.B. Sirks, 2004), p. $179=178$, señala: "Non licet immittire in alienum et quod servitute vel libertate conservanda, et ad hoc non solum conpetunt istae actiones reales confesoria et negatoria sed et interdicta possessoria, ut uti possidetis [...]" ("No se permite inmitir en lo ajeno, y el para conservar una servidumbre o proteger la libertad [del fundo] no sólo competen estas acciones [de fondo, confesoria y negatoria, sino también los interdictos posesorios como el uti possidetis"). 
los interdictos posesorios contra el ejercicio de servidumbre legítimamente constituida. Toda vez que sólo se puede inmitir cuando hay una servidumbre que lo autorice y quien no tiene una servidumbre, pero de igual manera inmite se arriesga a un juicio posesorio, el artículo termina de cerrar dicha idea expresando la íntima conexión que existe entre ambas.

La acción más general que tiene por función conservar la posesión es la llamada querella de amparo, la cual tiene por objeto impedir que el poseedor sea turbado o embarazado en su posesión (artículo 921). Es de destacar que el modelo empleado por Bello para las acciones posesorias se preocupa de aclarar perfectamente en qué se entiende por turbación o embarazo posesorio. Al respecto señala Juan Sala": "No compete solamente este interdicto contra otro que pretenda la misma posesión, sino también contra aquél que sin pretenderla nos inquieta y molesta en la que tenemos, no dejándonos usar de la cosa a nuestro arbitrio en sembrar, cavar, labrar, edificar o hacer otra cosa [...]. El que intenta en este caso el interdicto debe probar que es poseedor al tiempo de la contestación del pleito, y que el reo a quien conviene la turba en la posesión y en su conformidad pedir que se declare ser el poseedor, y mande, que el reo no le moleste en lo sucesivo en su posesión, y le pague los perjuicios que le haya causado por haberle molestado [...]".

Es decir, la acción tendría por finalidad defender al poseedor tanto contra quien pretende sustituirle en la posesión, como contra otros ataques de carácter material en la misma que le impidan el ejercicio de actos posesorios, tales como las inmisiones que realiza su vecino en su bien. No obstante, durante el siglo XX la comprensión de la función de la querella de amparo se ha visto más bien oscurecida, toda vez que la doctrina ha tendido a ignorar buena parte de la función protectora de la acción, limitando su aplicabilidad sólo a aquellos casos en que el turbador intenta sustituirse al poseedor en el control de la cosa. La idea proviene de la adopción por parte de Claro Solar de las ideas francesas sobre dicho interdicto y ha limitado fuertemente el alcance del mismo ${ }^{100}$; incluso existió quien postuló la improcedencia de la

\footnotetext{
${ }^{99}$ SALA, Juan, Ilustración del Derecho Real de España (Madrid, Imprenta Real, 1832), p. 258.

${ }^{100}$ Véase: Claro Solar, Luis, Explicaciones de Derecho civil chileno y comparado. De los bienes (Santiago, Nascimento, 1935), IV, p. 516. Este lamentable cercenamiento de la querella de amparo ha sido sostenido por lo más granado de nuestra civilística y ha servido de fundamento a numerosas sentencias. Citan esta obra, entre las sentencias más recientes: Corte Suprema, sentencia de 17 de marzo de 2008, rol o 6668-2006, “Transportes Ortiz y Alegría Ltda con Construcciones Mansilla Hermanos Ltda.", considerando 3; Corte Suprema, sentencia de 3 de noviembre de 2008, rol o 5563-2007, "Marcos Riveros Cofré con Luis Aravena Triviño", considerando $7^{\circ}$; Corte Suprema, sentencia de 26 de mayo de 2008, rol No 1144-2006, "Juan Rubio Jamett con Invecsur Limitada”, considerando $8^{\circ}$; Corte Suprema, sentencia de 22 de diciembre de 2004, rol
} 
acción de amparo por turbaciones materiales a la posesión ${ }^{101}$, aunque hoy en día tan alocada opinión, que retiraba todo posible efecto práctico a la institución, parece completamente descartada. No obstante, la función protectora amplia de la querella de amparo sigue inmanente en su naturaleza y con una ampliación de su función por parte de la jurisprudencia ésta

No 855-2004, "Lelvy Laureano Peña Lizama con Sociedad Cervecera CCU Chile Limitada”. En la doctrina, de una u otra forma, apoyan la estrecha visión de Claro Solar: Tocornal Gandarillas, Tomás, Interdictos posesorios (Memoria de prueba para optar al grado de licenciado de la Facultad de Ciencias Jurídicas y Sociales de la Universidad de Chile, Santiago, Imprenta Nacional, 1930), p. 29; Peñailillo Arevalo, Daniel, Los bienes. La propiedad y otros derechos reales (Santiago, Editorial Jurídica de Chile, 1997), p. 392. En todo caso, hasta comienzos del siglo XX había quien sostenía una visión más acorde al texto del Código, como por ejemplo en la memoria de prueba de De la Puente González, Rafael A., Acciones posesorias (Memoria de prueba para optar al grado de licenciado en la Facultad de Leyes i Ciencias Políticas de la Universidad de Chile, Santiago, Imprenta Encuadernación Universitaria, 1908), p. 41, donde se lee: "La turbación a que se refiere el núm. $2^{\circ}$ del mismo artículo 703 ante citado puede ser material o inmaterial. Será un acto de turbación material, por ejemplo, en el caso en que una persona rompe una muralla para pasar a cada momento a la casa de su vecino; i de turbación inmaterial en el caso de un derecho inscrito que se está publicando”. Sin embargo, una visión amplia de la querella de amparo que cubre también los casos de inmisiones la encontramos en la doctrina comparada y tímidamente en algunas obras nacionales: De Martino, Francesco, Del possesso, en Comentario del códice civile. Libro terzo: Della propietá (Bologna, Nicola Zanichelli, 1970), p. 122; Egea Fernández, Joan, Acción negatoria, inmisiones y defensa de la propiedad (Madrid, Marcial Pons, 1994), p. 100; Jiménez SALCEDo, María Carmen, El régimen jurídico de las relaciones de vecindad en Derecho romano (Córdoba, Universidad de Córdoba, 1999), p. 54. En Chile: Abdul-Malak Izam, Leyla, La disciplina de las inmisiones en el ordenamiento jurídico chileno: su aplicación práctica respecto al derecho a vivir en un medio ambiente libre de contaminación (Memoria para optar al grado de licenciado en Derecho por la Pontificia Universidad Católica de Chile, Santiago, 2006), p. 218.

${ }^{101}$ Esta es la extraña doctrina de don Humberto Trucco, que durante un tiempo tuvo bastante influencia. Según ésta, la única forma de turbar la posesión de un inmueble inscrito era intentar sustituirse en la inscripción de dominio, por lo que el objeto exclusivo de la querella de amparo era el improbable caso en que alguno fuese sorprendido por el actual poseedor en proceso de realizar una nueva inscripción ante el Conservador. Lo más alocado de esta teoría es que privaba completamente de sentido a la querella de amparo. Tal idea fue recibida en algunas obras de carácter doctrinario, como por ejemplo: Millán Vergara, Juan, Estudios Sobre las acciones o interdictos posesorios (Memoria de prueba para optar al grado de licenciado en la Facultad de Leyes i Ciencias Políticas de la Universidad de Chile, Concepción, Imprenta Chile, 1918), p. 26; y Pineda García, Teófilo, Algunas cuestiones sobre los interdictos posesorios $i$ en especial, de la querella de amparo (Memoria para optar al grado de licenciado en Leyes i Ciencias Políticas, Santiago, Imprenta Inglesa, 1923), p. 13; y debió ser discutida en serio por los tratadistas de prestigio hasta que Claro Solar impuso su visión de los interdictos posesorios. 
podría fácilmente recobrar su plena fuerza en la defensa de los intereses de los poseedores en las relaciones de vecindad. Trataremos de ello en detalle en el lugar oportuno, mas, de momento, hemos de pasar al estudio de las acciones posesorias especiales.

En el título $14^{\circ}$ del libro II, Bello recibió una compleja casuística relativa a los interdictos posesorios de las Partidas donde se trata específicamente de algunos casos frecuentes de turbaciones posesorias en las relaciones de vecindad (artículos 930-950) ${ }^{102}$. Éste es un conjunto de reglas bastante heterogéneas donde se crean algunas acciones posesorias especiales y se otorgan reglas específicas para tipos de inmisiones determinados que tienen valor respecto a todas las acciones posesorias en general. Buena parte de las disposiciones de este título fueron derogadas para ser trasladadas al Código de Aguas, por lo que en él se observan numerosos vacíos. Nosotros no trataremos aquí dichas materias, sino que nos limitaremos al examen de las disposiciones actualmente vigentes.

La primera acción que se trata es la denuncia de obra nueva, la cual tiene por finalidad impedir la construcción de obras ajenas en el suelo del poseedor, así como también impedir la construcción de obras en el inmueble vecino que impidan el ejercicio de servidumbres constituidas a favor del querellante. A pesar de su relevancia en las relaciones de vecindad, no parece ser especialmente interesante en materias de inmisiones, por lo que dejamos su tratamiento para especialistas en la materia ${ }^{103}$.

A continuación trata el Código de la denuncia de obra ruinosa, en virtud de la cual puede exigirse la reparación o derribo de los edificios cuyo mal estado hace temer perjuicios a sus vecinos. Es interesante toda vez que tal denuncia se corresponde con lo que la doctrina comparada ha denominado inmisiones de peligro ${ }^{104}$, que tiene lugar cuando la inactividad del vecino

${ }^{102} \mathrm{Al}$ respecto señala Claro Solar, Luis, Explicaciones de Derecho Civil Chileno y Comparado. De los Bienes (Santiago, Imprenta Cervantes, 1930), IV, p. 535: "El Código reúne en este título final del libro II acciones que llama posesorias especiales, muchas de las cuales miran, más que a la posesión, al ejercicio del derecho de propiedad y establecen restricciones o limitaciones a este ejercicio, a fin de evitar los daños o conflictos que la libertad de goce de los propietarios pudiera ocasionar". En el mismo sentido: Peñailillo Arevalo, Daniel, Los bienes. La propiedady otros derechos reales (Santiago, Editorial Jurídica de Chile, 1997), pp. 86-87.

${ }^{103}$ Respecto a ésta, tuvimos la oportunidad de leer en manuscrito el estudio de Huerta Molina, José Miguel - Rodríguez Diez, Javier, Suspensión interdictal de obras nuevas: desde la "operis novi nuntiatio" hasta el proyecto de Código Procesal; él que constituye un estudio acabado del problema, que esperamos ver publicado a la brevedad.

${ }^{104}$ Egea Fernández, Joan, Acción negatoria, inmisiones y defensa de la propiedad (Madrid, Marcial Pons, 1994), pp. 50-51. 
supone una perturbación posesoria, toda vez que pone en riesgo la posesión ajena impidiendo el ejercicio de actos posesorios ante la posibilidad de un derrumbe. No son los actos en lo propio, en este caso, los que inmiten en lo ajeno, sino más bien la omisión de actos de reparación y cuidado que amenazan con proyectar sus consecuencias en lo ajeno impidiendo la posesión pacífica del vecino. La indemnización de perjuicios sólo se dará si el derrumbe ocurre luego de notificada la denuncia (artículo 934), lo cual parece constituir un incentivo a que sean los propios ciudadanos los que velen por el buen estado de las construcciones.

A continuación entramos a las querellas posesorias que el Código de Procedimiento Civil llama interdictos especiales (artículo 549 CPC.). Por su naturaleza casuística, ni siquiera recibieron un nombre propio en la sistematización procedimental, aunque no por eso carecen de relevancia. La más interesante para nuestros fines es aquella fijada en el inciso $1^{\circ}$ del artículo 941 que establece un interdicto especial a favor del dueño de una casa en contra del vecino que mantenga depósitos de materias húmedas cerca de sus paredes: "El dueño de una casa tiene derecho para impedir que cerca de sus paredes haya depósitos o corrientes de agua, o materias húmedas que puedan dañarla".

Nosotros ya hemos tratado este artículo, indicando su origen en el Digesto, su recepción en las Partidas y su duplicación respecto al artículo 856 un poco más arriba, por lo que aquí nos limitaremos a analizar algunos aspectos de su dogmática. En principio, parece mucho más limitado que el artículo 856, toda vez que en lugar de entregar una lista ejemplar de cualquier tipo de obra de carácter inmisivo, se refiere específicamente sólo a depósitos de aguas y materias húmedas. El caso original del cual fue tomado trataba de un estercolero ${ }^{105}$, por lo que parece bastante adecuado para abarcar también vertederos, plantas de tratamientos de aguas y otros lugares semejantes. Sin embargo, el interdicto parece muy limitado, toda vez que establece como titular sólo al dueño, donde, al tratarse de interdictos posesorios, deberemos entender poseedor a título dominical, excluyéndose, por tanto, al cuasi poseedor o poseedor de un derecho real de uso, habitación o usufructo, como

${ }^{105}$ Dig. 8,5,17,2 (Alfenus, 2 digestorum): "Secundum cuius parietem vicinus sterculinum fecerat, ex quo paries madescebat, consulebatur, quemadmodum posset vicinum cogere, ut sterculinum tolleret. Respondi, si in loco publico id fecisset, per interdictum cogi posse, sed si in privato, de servitute agere oportere: si damni infecti stipulatus esset, possit per eam stipulationem, si quid ex ea re sibi damni datum esset, servare" ("Fui consultado acerca de un vecino que había hecho un estercolero en la pared, por el cual la deterioraba y de cómo litigar y hacerlo retirar el estercolero. Respondí que si afectaba a un lugar público, podía ser cogido por un interdicto, si a un lugar privado, se puede litigar por la [inexistencia] de la servidumbre. Si se estipuló caución de daños, puede litigarse por la estipulación para que repare los daños causados"). 
en las demás acciones posesorias (artículo 922). Otra seria limitante es que se expresa que debe ser dueño de una "casa", es decir, de una construcción con destinación habitacional.

La turbación expresada en el artículo es netamente de peligro, puesto que no exige que efectivamente se haya turbado la posesión o que haya acaecido el daño, sino que habilita a interponer tal interdicto contra la posibilidad del mismo. Es decir, no requiere que se demuestre la realidad de la inmisión, sino que basta con que eventualmente pueda producirse para que el interdicto pueda operar. Es seguramente este elemento el que ha servido de base para limitar de tal manera la procedencia del interdicto, sólo a casos de humedad y a favor de poseedores a título dominical de inmuebles habitacionales, puesto que no requiere demostrar la realidad de la perturbación posesoria, sino simplemente indicar verosímilmente su eventualidad. Si la perturbación efectivamente se produjese, además de este interdicto especial tendría aplicación la querella de amparo.

Respecto al eventual daño, este se refiere a toda la casa o recinto habitacional protegido, no exclusivamente a las paredes, como revela el femenino singular utilizado por Bello: "dañarla”, pues si se refiriese a las paredes debiera usar el plural. El tipo de daño que puede sobrevenir no se encuentra especificado, por lo que entendemos que puede referirse a todo tipo de inmisión que, de producirse, pudiese resultar perjudicial, como aquellas de humedad o de malos olores, desvirtuando la finalidad habitacional del inmueble. Esto puede resultar muy interesante en la actualidad, baste pensar en el caso de Pelequén.

Los incisos segundo, tercero y cuarto del artículo en comento son la recepción de la constitución imperial de Zenón sobre distancias en el propio Código Civil. Constituye una limitación al dominio y existe una acción posesoria para el caso de violarse dicha limitación, pero no tiene mayor relevancia para nuestro estudio. Otro tanto diremos de los artículos 942 y 943 , que son una aplicación del interdicto de glande legenda, que aunque muy interesantes en sí, no tienen mayor relación con el problema central de este estudio.

Llegamos, así, a la última acción involucrada en el título de las acciones posesorias especiales, aquélla popular establecida por los artículos 948 y 949 . El primero expresa: "La municipalidad y cualquiera persona del pueblo tendrá, en favor de los caminos, plazas u otros lugares de uso público, y para la seguridad de los que transitan por ellos, los derechos concedidos a los dueños de heredades o edificios privados. Y siempre que a consecuencia de una acción popular haya de demolerse o enmendarse una construcción, o de resarcirse un daño sufrido, se recompensará al actor, a costa del querellado, con una suma que no baje de la décima, ni exceda a la tercera parte de lo que cueste la demolición o enmienda, $o$ el resarcimiento del daño; sin perjuicio de que si se castiga el delito o negligencia 
con una pena pecuniaria, se adjudique al actor la mitad". El artículo 949 dice: "Las acciones municipales o populares se entenderán sin perjuicio de las que competan a los inmediatos interesados".

Ambos artículos son de sumo interés, no sólo para el estudio de los problemas de inmisiones y de relaciones de vecindad, sino para el establecimiento de un Derecho ambiental de corte privado en nuestro sistema jurídico. El punto de partida se encuentra en las acciones posesorias de que es titular el poseedor a título dominical de una heredad, a saber, querella de amparo, de restablecimiento, de obra nueva, de obra ruinosa y la especial del artículo 941. Todas estas acciones posesorias, de conformidad con el Código Civil, pueden ser ejercidas tanto por los municipios, como por cualquier ciudadano cuando el bien cuya perturbación se quiere impedir es una plaza, un camino o cualquier otro lugar de uso público. Esta es una acción de carácter popular, derivada directamente del interdicto romano ne in loco publico flat, cuya función era, justamente, la protección del uso común de los lugares de uso público, el cual fue contemplado específicamente en las Partidas ${ }^{106}$ y de ahí recibido en el Código Civil.

Textualmente se encuentra tomado de Dig. 43,7,1, donde se establece ${ }^{107}$ : "A cualquiera le es permitido accionar a favor de lo público en cuanto concierna a su uso, como por ejemplo en favor de las vías públicas o de los caminos públicos. Y pienso que cualquiera puede postular este interdicto”.

El razonamiento que subyace al interdicto en cuestión es que los lugares de uso público aprovechan a todos los ciudadanos, por lo que, en caso de deteriorarse éstos, pueden considerarse individualmente afectados todos y cada uno de ellos. En palabras de Alburquerque 108 "debe permitirse a todo

${ }^{106}$ En efecto, en el "Proyecto de 1853", en el artículo 1093, que se corresponde con el actual 948, Bello señala en nota al pie que este sería una modificación de una disposición de las Partidas, específicamente la part. III, tit. $32^{\circ}$, ley $10^{a}$ que dispone la titularidad de una acción especial de derribo de edificios, sean nuevos o viejos, cuando estos sean peligrosos para los vecinos. Sin embargo, el interdicto romano ne in loco publico fiat aparece más bien recogida en las leyes $22^{\mathrm{a}}$ a $24^{\mathrm{a}}$, del mismo título $32^{\circ}$ de la part. III, donde se otorgan acciones populares para prevenir la construcción de obras en lugares públicos. Su alcance, sin embargo, parece mucho más restringido que aquél del interdicto romano. Acerca de este proceso, véase: Delgado, Verónica, La protección del medio ambiente a través de las acciones populares del artículo 948 del Código Civil de Andrés Bello: un estudio histórico-comparativo, en Sesquicentenrio del Código Civil de Andrés Bello (Santiago, LexisNexis, 2005).

${ }^{107}$ Dig. 43,7,1 (Pomponius, 30 ad Sabinum): “Cuilibet in publicum petere permittendum est id, quod ad usum omnium pertineat, veluti vias publicas, itinera publica: et ideo quolibet postulante de his interdicitur".

${ }^{108}$ Alburquerque, Juan Miguel, La protección o defensa del uso colectivo de las cosas de dominio público: especial referencia a los interdictos "de publicis locis" ("loca, itinere, viae, flumina, ripae”) (Madrid, Dykinson, 2002), p. 39. 
el mundo el uso general de lo que es público, es decir, a todos los miembros de la colectividad. Cabe resaltar que para cumplir esta finalidad, se otorga un interdicto a quien quiera solicitarlo". El interdicto romano comprendía diversas formulaciones "todas ellas con la finalidad de evitar que se haga algo en lugar o camino público y, en general, con la pretensión de proteger todo locus publicus (aereae, insulae, agri, itinera publica, viae publica) de posibles obras no autorizadas, así como de perturbaciones o inmisiones que causen algún tipo de daño a alguien o deterioren la vía pública o el camino." ${ }^{109}$

En relación al artículo 948, al igual que el interdicto romano, éste entrega dos ejemplos para ilustrar los lugares públicos, las vías y caminos, agregando luego la cláusula general "u otros lugares de uso público" para especificar a favor de qué tipo de bienes puede interponerse. Por lugares públicos, en el caso del interdicto romano, parece entenderse, más bien, lugares destinados al uso público ${ }^{110}$, según la famosa definición de Celso contenida en Dig. $18,1,6 \mathrm{pr}^{111}$ : "[...] porque los lugares sagrados y religiosos no están dentro del comercio, como tampoco los públicos, entendiendo por aquéllos los que no están en el peculio del pueblo [es decir, los bienes fiscales] sino los que están destinados al uso público, como es el caso del Campo de Marte".

Es de destacar que tal concepto fue recibido por el Código Civil en el artículo 589 que establece que aquellos bienes nacionales cuyo uso pertenece a toda la nación, "como el de las calles, plazas, puentes y caminos, el mar adyacente y sus playas" se denominan bienes públicos o bienes nacionales de uso público. Para el caso de nuestra acción posesoria especial del artículo 948, la mención a los lugares públicos remite directamente a dicho concepto. Es más, incluso los ejemplos citados en el 948 coinciden con aquellos referidos en el artículo 589, lo cual refuerza dicha idea.

En cuanto a la finalidad de tal interdicto, esta es doble. Por una parte puede buscar la protección de los lugares mismos o también la seguridad de los posibles transeúntes por tales lugares. En efecto, el uso del copulativo " $y$ " no deja más alternativa que inclinarse por una doble función.

Las acciones otorgadas son las mismas de un poseedor de la cosa, aunque evidentemente quien intenta la acción no puede ser poseedor de dicho bien nacional de uso público sino en conjunto con la nación toda. Serán, por tanto,

${ }^{109}$ Alburquerque, Juan Miguel, La protección o defensa del uso colectivo de las cosas de dominio público: especial referencia a los interdictos "de publicis locis" ("loca, itinere, viae, flumina, ripae") (Dykinson, Madrid, 2002), p. 57.

${ }^{110}$ Ibíd., pp. 86-104.

${ }^{111}$ Dig. 18,1,6 pr. (Pomponius, 9 ad Sabinum): "Sed Celsus filius ait hominem liberum scientem te emere non posse nec cuiuscumque rei si scias alienationem esse: ut sacra et religiosa loca aut quorum commercium non sit, ut publica, quae non in pecunia populi, sed in publico usu habeatur, ut est Campus Martius". 
aplicables, las acciones de amparo, con su régimen de inmisiones implícito, la de restablecimiento, en caso que alguno se haya apropiado del bien, la de obra nueva, de obra ruinosa y la especial del artículo 941 .

En fin, incluso se establece un premio para quien la intente, con el equivalente a una fracción del costo de la demolición de la obra. Verdaderamente, este interdicto tiene una gran potencia y parece único dentro de la tradición codificadora del siglo XIX, recepción de la mejor casuística romana encaminada a preservar los bienes públicos de inmisiones realizadas por particulares. Llama la atención, sin embargo, el escaso interés que ha suscitado tal disposición en la dogmática nacional, que generalmente la ignora, así como su pésima interpretación en algún fallo que rechaza aplicarla ${ }^{112}$.

Pasamos, finalmente, a cierta norma especial que recibe poquísima atención y que tiene muchísima importancia en el contexto de las acciones posesorias. Nos referimos al artículo 937 que dispone: "Ninguna prescripción se admitirá contra las obras que corrompan el aire y lo hagan conocidamente dañoso".

Esta disposición no sólo establece la imprescriptibilidad de las acciones posesorias en cuanto se trate de obras que corrompan el aire, sino que confirma la aplicabilidad de la función de defensa de las inmisiones que tienen dichas acciones. Esta norma hace excepción al principio de prescriptibilidad de las acciones posesorias en cuanto el acto turbatorio de la posesión contra el cual acciona consista en la inmisión de humos o malos olores, por lo que se aplicaría no sólo a la denuncia de obra nueva, de obra ruinosa, al interdicto especial del artículo 941 o al interdicto popular del 948, sino también a la querella de amparo, en la medida que la posesión del bien esté siendo embarazada por la contaminación atmosférica emitida por el demandado. En verdad, en un país que padece fuertes problemas de contaminación ambiental, muchas veces imputables a la actividad de una industria determinada, resulta sorprendente que tales artículos no reciban una mayor aplicación.

${ }^{112}$ Nos referimos específicamente al caso "Alumysa”, respecto del cual la Corte Suprema confirmó un fallo que negaba la aplicación de este artículo para defender lugares de uso público, a saber lagos públicos que iban a ser destruidos por la construcción de una central hidroeléctrica. La Corte de Apelaciones de Coyhaique había desestimado la acción porque la demandante no habría acreditado ni las circunstancias necesarias para la aplicación de la acción especial del artículo 948, interpretando de una manera absurdamente restrictiva los supuestos de la acción, al decir que sólo procedería para la defensa de caminos, y olvidando el título ejemplar de los casos citados en el precepto, ni la querella de amparo, por no ser la demandante poseedora de los lagos en cuestión. En verdad la sentencia es mala y merecidamente criticable. Véase: Corte Suprema, sentencia de 30 de diciembre de 2003, rol No 1354-2003. 


\section{Conclusiones}

A modo de conclusión podemos señalar que el Código Civil contiene una normativa que regula las relaciones de vecindad y el problema de las inmisiones, la cual se encuentra dispersa en tres lugares específicos del mismo.

El principio general de no inmitir en los bienes ajenos que permite aplicar la teoría de las inmisiones a las relaciones de vecindad se encuentra en la coletilla final del artículo 582 que define el dominio como limitado en razón del derecho ajeno. Este es un principio general en materia de bienes, por lo que debe entenderse que el ejercicio de las facultades de dominio siempre encuentra su límite en la no realización de actos que afecten el ejercicio de actos de uso, goce o disposición de otros titulares dominicales, por lo que la penetración de las emisiones producidas en un predio en otro se encuentra, en principio, prohibida.

Por otra parte, la regulación de las relaciones de vecindad se recogió a propósito de las servidumbres legales, donde, pese a las confusiones derivadas de su modelo francés, se establece la prohibición de realizar actos que resulten inmisivos en los bienes ajenos, salvo que exista una servidumbre legal que lo autorice. A pesar de no estar expresamente contemplada la acción negatoria en nuestro Código, parece evidente que en caso que se realicen actos de carácter inmisivo, puede el dueño del bien interponer una acción de fondo de carácter meramente declarativo en que se vindique la libertad del fundo en cuestión y, por tanto, la cesación de los actos inmisivos. Si se quiere denominar negatoria tal acción, como ha hecho toda la tradición dogmática desde la época romana hasta el presente, es una cuestión de detalle.

Finalmente, encontramos que la materia se encuentra extensamente tratada en materia posesoria a través de la querella de amparo y de las acciones posesorias especiales, entre las cuales existen algunas que tienen especial importancia en materia de inmisiones y que serían suficientes para construir un verdadero sistema de protección ambiental privado en el derecho nacional. Si estas acciones no han recibido adecuada aplicación, esto se debe, principalmente, a su escaso tratamiento por parte de la doctrina, que las convierte en verdaderas desconocidas dentro del Código Civil. Por lo demás, la tradición jurídica nacional centró su actividad en la recepción de las teorías francesas de finales del XIX para explicar Derecho civil y el marco dentro del cual se ha desarrollado la teoría de las inmisiones y su tratamiento no corresponde a tal espacio jurídico, sino más bien a Alemania e Italia, donde tendrán su desarrollo más marcado. 


\section{BiBLIOGRAFÍA}

Abdul-Malak Izam, Leyla, La disciplina de las inmisiones en el ordenamiento jurídico chileno: su aplicación práctica respecto al derecho a vivir en un medio ambiente libre de contaminación (Memoria para optar al grado de licenciado en Derecho por la Pontificia Universidad Católica de Chile, Santiago, 2006).

Accursius, Digestum Vetus seu Pandectarum Iuris Civilis (Venetiis, 1592), I.

Alburguergue, Juan Miguel, La protección o defensa del uso colectivo de las cosas de dominio público: especial referencia a los interdictos "de publicis locis" ("loca, itinere, viae, flumina, ripae") (Madrid, Dykinson, 2002).

Alessandri Rodríguez, Arturo, De los bienes (Santiago, Zamorano y Caperán, 1937).

Algarra Prats, Esther, La defensa jurídico-civil frente a humos, olores, ruidos y otras agresiones a la propiedad y a la persona (Madrid, McGraw-Hill, 1995).

Amunátegui Perelló, Carlos Felipe, "No siendo contra derecho ajeno": hacia la formulación de una teoría de las inmisiones en nuestro Código Civil, en Revista Chilena de Derecho, 36 (2009) 3.

Amunátegui Perelló, Carlos Felipe, Inmisiones y querella de amparo. Contribución a la historia dogmática de un caso de responsabilidad objetiva, en Libro de amigos dedicado al profesor Italo Merello (Valparaíso, Ediciones Universitarias de Valparaíso, 2011).

Barrientos Grandón, Javier, Juan Sala Bañuls (1731-1806) y el Código Civil de Chile (1855), en Revista de Estudios Histórico-Jurídicos, 31 (2010).

Bartoli a SAXoferrato, In primam Digesti Veteris pertem commentaria (Augusta Taurinorum, Nicolau Bevilaquam, 1574, reimpresión de A.J.B. Sirks, Maastricht, 2004).

Bello, Andrés, Instituciones de Derecho romano (Santiago, Imprenta Nacional, 1878).

Bello, Andrés, Obras completas (Santiago, Impreso por Pedro G. Ramírez, 1888), XII.

BeLlo, Andrés, Obras completas (Santiago, Nascimento, 1952), III.

Bello, Andrés, Proyecto de Código Civil, en Obras completas (Santiago, Nascimento, 1932), V.

Biondi, Biondo, La categoria romana delle "servitutes" (Milano, Vita e Pensiero, 1936).

Biondi, Biondo, Le serivtù prediali nel diritto romano (Milano, Giuffrè, 1969.

Biondi, Biondo, Le servitù (Milano, Giuffrè, 1967).

Bonfante, Pietro, Corso di Diritto romano. La propietà (Milano, Giuffrè, 1966), II, 1.

Capogrossi Colognesi, Luigi, Actor and Defendant in Negatoria Servitus, en CaIrns, John W. - Robinson, Olivia F. (editores), Critical Studies in Ancient Law, Comparative Law and Legal History (Oxford and Portland, Oregon, 2001).

Claro Solar, Luis, Explicaciones de Derecho Civil chileno y comparado. De los Bienes (Santiago, Imprenta Cervantes, 1930), I.

Claro Solar, Luis, Explicaciones de derecho civily comparado. De los bienes (Santiago, Nascimento, 1935), IX, 4.

Codex Iustinianus (Ed. Krueger). 
David, Jacqueline, Les solidarités juridiques de voisinage, de l'ancien Droit à la codification, en Revue Historique de Droit Français et Étranger, 72 (1994) 3.

De la Puente González, Rafael A., Accionesposesorias (Memoria de prueba para optar al grado de licenciado en la Facultad de Leyes i Ciencias Políticas de la Universidad de Chile, Santiago, Imprenta Encuadernación Universitaria, 1908).

De Martino, Francesco, D. 8.5.8.5: i rapporti di vicinato e la tipicità delle servitú, en Diritto, Economia e società nel mondo romano (Jovene, Napoli, 1995), I.

De Martino, Francesco, Delpossesso, en Comentario del códice civile. Libro terzo. Della proprietá (Bologna, Nicola Zanichelli Editore, 1970).

Del Arco Torres, Miguel Ángel - Pons González, Manuel, Régimen jurídico de las servidumbres (Granada, Comares, 2002).

Delgado, Verónica, La protección del medio ambiente a través de las acciones populares del artículo 948 del Código Civil de Andrés Bello: un estudio histórico-comparativo, en Sesquicentenrio del Código Civil de Andrés Bello (Santiago, LexisNexis, 2005).

Delvincourt, C., Cours de Code Civil (Paris, Videcoq, 1834), I.

Díaz Romero, María del Rosario, La acción negatoria frente a inmisiones en el derecho depropiedad, en Estudios jurídicos en homenaje al profesor Luis Diez-Picazo (Madrid, Thomson, 2003), III.

Domat, Jean, Oeuvres complètes (Paris, Alex-Gobelet, 1835).

Donelli, Hugonis, Opera Omnia. Comentariorum de iure civili (Maceratae, Osualdi Hilligeri, 1839), III.

Egea Fernández, Joan, Acción negatoria, inmisiones y defensa de la propiedad (Madrid, Marcial Pons, 1994).

Falcone, Giuseppe, Note historique sur la définition législative de la servitude (article 637 Code Napoléon - article 1027 Cod. Civ. It.), en Revue Historique de Droit Français et Étranger, 79 (2001) 1.

Falcone, Giuseppe, Ricerche sull'origine dell'interdetto "uti possidetis", en Annali del Seminario Giuridico dell'Università di Palermo, 44 (1996).

Fenet, P. A., Recueil complet des travaux préparatoires du Code Civil (Paris, 1827), XI.

García Goyena, Florencio, Concordancia motivos y comentarios del Código Civil español (Madrid, Imprenta de la Sociedad Tipográfico, 1852).

García Sánchez, Justo, Teoría de la “immissio" (Oviedo, Universidad de Oviedo, 1999).

Gayo, Institutiones (ed. Baviera).

GuYot, Répertoire universel et raisonné de jurisprudence civil, criminelle, canonique et bénéficiale (Paris, Panckoucke, 1783), CVIII.

Heineccius, Ioann. Christian, Institutiones iuris civilis (Gottingae, Dieterich, 1800).

Huerta Molina, José Miguel - Rodríguez Diez, Javier, Suspensión interdictal de obras nuevas: desde la "operis novi nuntiatio" hasta el proyecto de Código Procesal (inédito).

Iustinianus, Digesta (ed. Mommsen).

Jani a Costa, Praelectiones ad illustriores quosdam titulos locaque selecta iuris civilis (Lugduni Batavorum, B. Voorda, 1723).

JHERING, Rudolf von, Jahrbücher für die Dogmatic des heutigen römischen und deutchen Privatrechts (1863). 
Jiménez Salcedo, María Carmen, El régimen jurídico de las relaciones de vecindad en Derecho romano (Córdoba, Universidad de Córdoba, 1999).

Lathorp Gómez, Fabiola, Procedencia de la acción meramente declarativa del dominio en el Derecho chileno, en Ius et Praxis, 17 (2011) 2.

Lázaro Guillamón, Carmen, La acción negatoria (Valencia, 2007, Tirant lo Blanch).

Lira Urquieta, Pedro, El Código Civil y el nuevo Derecho (Santiago, Nascimento, 1944).

Llácer Matacás, M. R., Relaciones de vecindad, en VV. AA., Tratado de servidumbres (Navarra, Aranzadi, 2002).

Meerman, Gerard, Novus thesaurus iuris civilis et canonici (Rotterdam, Petrus de Hond, 1751).

Míguez NúÑ̃z, La acción negatoria, en Revista de Derecho de la Universidad Católica de la Santísima Concepción, 12 (2004).

Millán Vergara, Juan, Estudios Sobre las acciones o interdictosposesorios (Memoria de prueba para optar al grado de licenciado en la Facultad de Leyes i Ciencias Políticas de la Universidad de Chile, Concepción, Imprenta Chile, 1918).

Montes, Vicente, La propiedad privada en el sistema del Derecho civil contemporáneo (Madrid, Civitas, 1980).

Pacheco Caballero, Francisco, Las servidumbres prediales en el Derecho Histórico español (Lleida, Pagés Editors, 1991).

Padial Albás, Adoración - Toldrà Roca, María Dolores, El derecho de propiedad y otros derechos reales en el derecho civil de Cataluña (Valencia, Tirant lo Blanch, 2008).

Pardesus, J. M., Traité des servitudes ou services fonciers (Paris, Thorel, 1838), I.

PARICIO, Javier, La denuncia de obra nueva en el Derecho romano clásico (Barcelona, Bosch, 1982).

Peñailillo Arevalo, Daniel, Los bienes. La propiedad y otros derechos reales (Santiago, Editorial Jurídica de Chile, 1997).

Pescio, Victorio, Manual de Derecho civil (Santiago, Editorial Jurídica, 1978).

Piccinelli, Ferdinando, Studi e ricerche intorno alla definizione dominium est ius utendi et abutendi re sua quatenus iuris ratio patitur (reimpresión Napoli, Jovene, 1980).

Pineda García, Teófilo, Algunas cuestiones sobre los interdictosposesorios i en especial, de la querella de amparo (Memoria para optar al grado de licenciado en Leyes i Ciencias Políticas, Santiago, Imprenta Inglesa, 1923).

Planiol, Marcel, Traité élémentaire de Droit civil (Paris, Librairie Générale de Droit \& Jurisprudence, 1915), I.

Pothier, Robert-Joseph, Obras Completas. Tratado del derecho de dominio de la propiedad (Barcelona, Imprenta de la viuda e hijos de J. Subirana, 1882), VII.

Pothier, Robert-Joseph, Coutume d'Orléans, en OEuvres (Paris, Videcoq, 1845), I.

Pothier, Robert-Joseph, Traité de la possession, en Oeuvres (Paris, Delamotte, 1846), IX.

Pothier, Robert-Joseph, Traité du droit de domaine de propriété, en Ouvres (Paris, Pichon-Béchet, 1827), VII.

Rivera Serrano, Manuel, Servidumbre de medianeria (Granada, Comares, 1999).

RÜFNER, Thomas, The Roman Concept of Ownership and the Medieval Doctrine of Dominium Utile, en CaIrns, John W. - Du Plessis, Paul J. (editores), The Creation of Ius Commune. From Casus to Regula (Edinburgh University Press, 2010). 
SAla, Juan, Ilustración del Derecho Real de España (Madrid, Imprenta Real, 1832).

Tocornal Gandarillas, Tomás, Interdictos posesorios (Memoria de prueba para optar al grado de licenciado de la Facultad de Ciencias Jurídicas y Sociales de la Universidad de Chile, Santiago, Imprenta Nacional, 1930.

Troplong, Raymond Théodore, Le droit civil expliqué.De la prescription (Paris, Charles Hingray, 1835), I.

Vodanovic, Antonio, Derecho Civil (Santiago, Nascimento, 1940).

Vodanovic, Antonio, Derecho civil basado en las explicaciones de los profesores de la Universidad de Chile Arturo Alessandri Rodríguez y Manuel Somarriva Undurraga. De los sujetos y los objetos del Derecho (Santiago, Nascimento, 1940), II. 